\title{
Article \\ The Individual Effects of Cyclin-Dependent Kinase Inhibitors on Head and Neck Cancer Cells-A Systematic Analysis
}

\author{
Nina Schoenwaelder ${ }^{1, *}$, Inken Salewski ${ }^{1}$, Nadja Engel ${ }^{2}{ }^{(0}$, Mareike Krause ${ }^{1}\left(\mathbb{D}\right.$, Björn Schneider $^{3}{ }^{(0)}$,

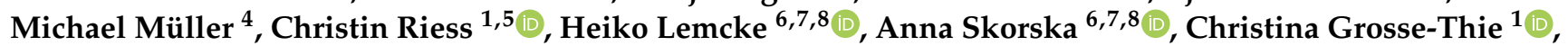 \\ Christian Junghanss ${ }^{1}$ and Claudia Maletzki ${ }^{1}$ (D)
}

1 Department of Internal Medicine, Medical Clinic III—Hematology, Oncology, Palliative Medicine, University Medical Center Rostock, 18057 Rostock, Germany; Inken.salewski@med.uni-rostock.de (I.S.); mareike.krause@uni-rostock.de (M.K.); Christin.riess@med.uni-rostock.de (C.R.); christina.grosse-thie@med.uni-rostock.de (C.G.-T.); christian.junghanss@med.uni-rostock.de (C.J.); claudia.maletzki@med.uni-rostock.de (C.M.)

2 Department of Oral and Maxillofacial Surgery, Facial Plastic Surgery, University Medical Center Rostock, 18057 Rostock, Germany; Nadja.Engel@med.uni-rostock.de

3 Institute of Pathology, University Medical Center Rostock, Strempelstr.14, 18057 Rostock, Germany; bjoern.schneider@med.uni-rostock.de

4 Core Facility for Cell Sorting \& Cell Analysis, Laboratory for Clinical Immunology, University Medical Center Rostock, 18057 Rostock, Germany; Michael.Mueller2@med.uni-rostock.de

5 University Children's Hospital, Rostock University Medical Centre, 18057 Rostock, Germany

6 Department of Cardiac Surgery, Reference and Translation Center for Cardiac Stem Cell Therapy (RTC),

check for updates

Citation: Schoenwaelder, N.; Salewski, I.; Engel, N.; Krause, M.; Schneider, B.; Müller, M.; Riess, C.; Lemcke, H.; Skorska, A.; Grosse-Thie, C.; et al. The Individual Effects of Cyclin-Dependent Kinase Inhibitors on Head and Neck Cancer Cells-A Systematic Analysis. Cancers 2021, 13, 2396. https://doi.org/10.3390/ cancers13102396

Academic Editor: Samuel C. Mok

Received: 1 March 2021

Accepted: 11 May 2021

Published: 15 May 2021

Publisher's Note: MDPI stays neutral with regard to jurisdictional claims in published maps and institutional affiliations.

Copyright: (c) 2021 by the authors. Licensee MDPI, Basel, Switzerland. This article is an open access article distributed under the terms and conditions of the Creative Commons Attribution (CC BY) license (https:/ / creativecommons.org/licenses/by/ $4.0 /)$. University Medical Center Rostock, 18057 Rostock, Germany; Heiko.Lemcke@med.uni-rostock.de (H.L.); anna.skorska@med.uni-rostock.de (A.S.)

7 Department of Cardiology, University Medical Center Rostock, 18059 Rostock, Germany

8 Department Life, Light \& Matter, Faculty of Interdisciplinary Research, University Rostock, 18059 Rostock, Germany

* Correspondence: nina.schoenwaelder@med.uni-rostock.de; Tel.: +49-381-494-5764

Simple Summary: This study examined the therapeutic potential of a combined therapy approach, based on clinical approved drugs (5-FU, Cisplatin, cetuximab) and cyclin-dependent kinase inhibitors (CDKi, dinaciclib, palbociclib, THZ1). We identified individual effects on head and neck squamous cell carcinoma cells, including induction of apoptosis/necrosis, and senescence as well as reduced invasiveness. Besides, we describe the relevance of the sequential timing of each combination partner to achieve synergistic effects. Another interesting finding of our study is the upregulation of immunologically relevant molecules on the tumor cell surface under certain CDKi-drug combinations. Here, dinaciclib and palboclicb had highest impact on immunogenicity, which even exceeded effects of the standard drugs. Finally, a therapeutic in vivo approach partially confirmed cell line-based results. Here, effective tumor growth control was seen when cisplatin was combined with dinaciclib. However, antitumoral effects were highly individual and nicely confirm the heterogeneity of this tumor entity.

Abstract: Cyclin-dependent kinase inhibitors (CDKi's) display cytotoxic activity against different malignancies, including head and neck squamous cell carcinomas (HNSCC). By coordinating the DNA damage response, these substances may be combined with cytostatics to enhance cytotoxicity. Here, we investigated the influence of different CDKi's (palbociclib, dinaciclib, THZ1) on two HNSCC cell lines in monotherapy and combination therapy with clinically-approved drugs (5-FU, Cisplatin, cetuximab). Apoptosis/necrosis, cell cycle, invasiveness, senescence, radiation-induced $\gamma$-H2AX DNA double-strand breaks, and effects on the actin filament were studied. Furthermore, the potential to increase tumor immunogenicity was assessed by analyzing Calreticulin translocation and immune relevant surface markers. Finally, an in vivo mouse model was used to analyze the effect of dinaciclib and Cisplatin combination therapy. Dinaciclib, palbociclib, and THZ1 displayed anti-neoplastic activity after low-dose treatment, while the two latter substances slightly enhanced radiosensitivity. Dinaciclib decelerated wound healing, decreased invasiveness, and induced MHC-I, accompanied by high amounts of surface-bound Calreticulin. Numbers of early and late apoptotic 
cells increased initially $(24 \mathrm{~h})$, while necrosis dominated afterward. Antitumoral effects of the selective CDKi palbociclib were weaker, but combinations with 5-FU potentiated effects of the monotherapy. Additionally, CDKi and CDKi/chemotherapy combinations induced MHC I, indicative of enhanced immunogenicity. The in vivo studies revealed a cell line-specific response with best tumor growth control in the combination approach. Global acting CDKi's should be further investigated as targeting agents for HNSCC, either individually or in combination with selected drugs. The ability of dinaciclib to increase the immunogenicity of tumor cells renders this substance a particularly interesting candidate for immune-based oncological treatment regimens.

Keywords: targeted therapy; combination strategies; immunogenic cell death; xenograft model

\section{Introduction}

Mammalian cell cycle is controlled by cyclin dependent kinases (CDKs) [1]. In tumors, CDKs are dysregulated and CDK/cyclin complexes frequently overexpressed [2-4]. Tumor cells bypass the CDK4/6-Rb axis because it is critical for cell cycle entry and cell proliferation [5]. The knowledge about these mutations is a chance to identify molecular targets for pharmacological interventions [6]. Indeed, several CDK inhibitors (CDKi's) been developed for cancer treatment. Additionally to the highly selective and FDA-approved CDKi's palbociclib, ribociclib, and abemaciclib, multi- and pan-CDKi's are now entering clinical trials. These include, among others, dinaciclib that targets CDK1, CDK2, CDK5, and CDK9 [7,8], and THZ1, which is active against CDK7, CDK12, and CDK13 [9,10].

Advances in understanding of pathobiology and molecular characteristics have contributed to the introduction of novel therapy approaches. Still, the treatment of solid tumors remains challenging. Additionally to intrinsic resistance mechanisms, the development or outgrowth of single subclones after therapy promotes immune escape and complicates precision medicine.

Head and neck cancers are paradigmatic for tumor heterogeneity. They can be found in the oral cavity, pharynx, larynx, salivary glands, nasal cavity, and paranasal sinuses [11]. The predominant histological type of head and neck tumors is squamous cell carcinomas (HNSCC) [11]. HNSCC is the 7th most common cancer worldwide [11-13]. Risk factors include tobacco, alcohol, and human papillomavirus (HPV) infection. The latter drives tumor formation in the oropharynx with distinct clinical, histopathological, and molecular characteristics [14,15]. Around 58\% of the patients present with loco-regionally advanced disease at diagnosis and this patient cohort has a poor prognosis [11]. Hence, the implementation of targeted therapies in standard treatment schedules constitutes a promising and urgently needed approach for improving treatment and outcome. In 2019, a multicenter, multigroup, phase 2 trial reported promising activity outcomes in patients with platinum-resistant or cetuximab-resistant HPV-unrelated HNSCC receiving palbociclib and cetuximab [16]. Though combination strategies are promising, the sequential timing of each combination partner remains debatable [17-19]. To move forward, we here employed simultaneous and sequential combination strategies of clinically approved therapeutics and CDKi's for treating HNSCC with the aim to identify the best strategy.

\section{Results}

\subsection{CDKi Treatment Impairs Viability and Exerts Synergistic Effects in Combination Therapy}

UT-SCC-14 and UT-SCC-15 were used as in vitro cell culture models, since these cells are representative for primary and recurrent HNSCC. Both cell lines were susceptible to standard drugs and CDKi's in clinically relevant doses (below $1 \mu \mathrm{M}$ for CDKi's and $\leq 90 \mu \mathrm{g} / \mathrm{mL}$ for cytostatic drug), as determined in preliminary experiments. For combination experiments, standard drugs 5-Fluorouracil (5-FU), Cisplatin, and cetuximab as well as CDKi's (dinaciclib, palbociclib, THZ1) were applied in doses below the $\mathrm{IC}_{50}$ (Figure 1A,B; cetuximab is the only exceptions, here $\mathrm{IC}_{50}$ doses were used). The time course of treatment 
considered each cell lines' doubling times and attempted to mimic the in vivo situation.

Therefore, cells received two treatment cycles of $72 \mathrm{~h}$.

\begin{tabular}{ccc} 
A & \multicolumn{3}{c}{$1 \times 72 \mathrm{~h}$ treatment } \\
\hline \multirow{2}{*}{ drug } & UT-SCC-14 & UT-SCC-15 \\
\cline { 2 - 3 } & Biomass in relation to control [\%] \\
\hline \multirow{2}{*}{ 5-FU } & 72 & 92 \\
Cisplatin & 71 & 106 \\
cetuximab & 45 & 74
\end{tabular}

\section{B $2 \times 72 \mathrm{~h}$ treatment - simultaneous approach}

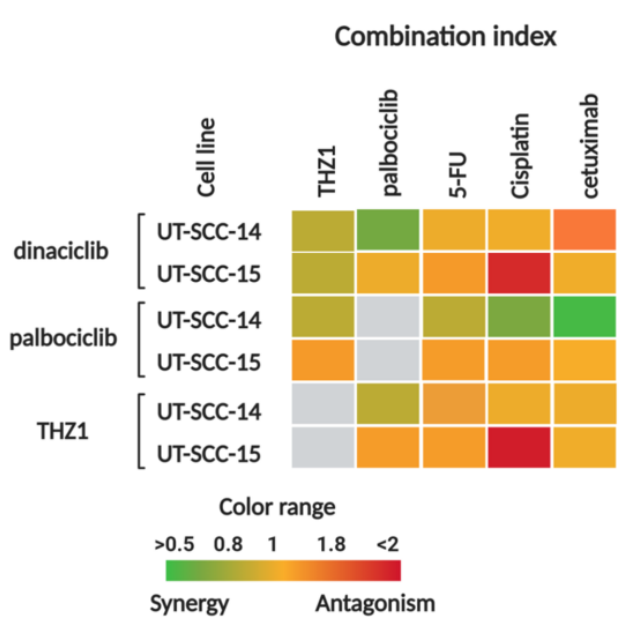

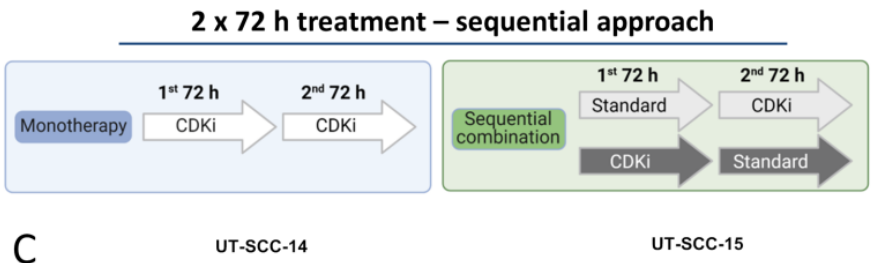

C
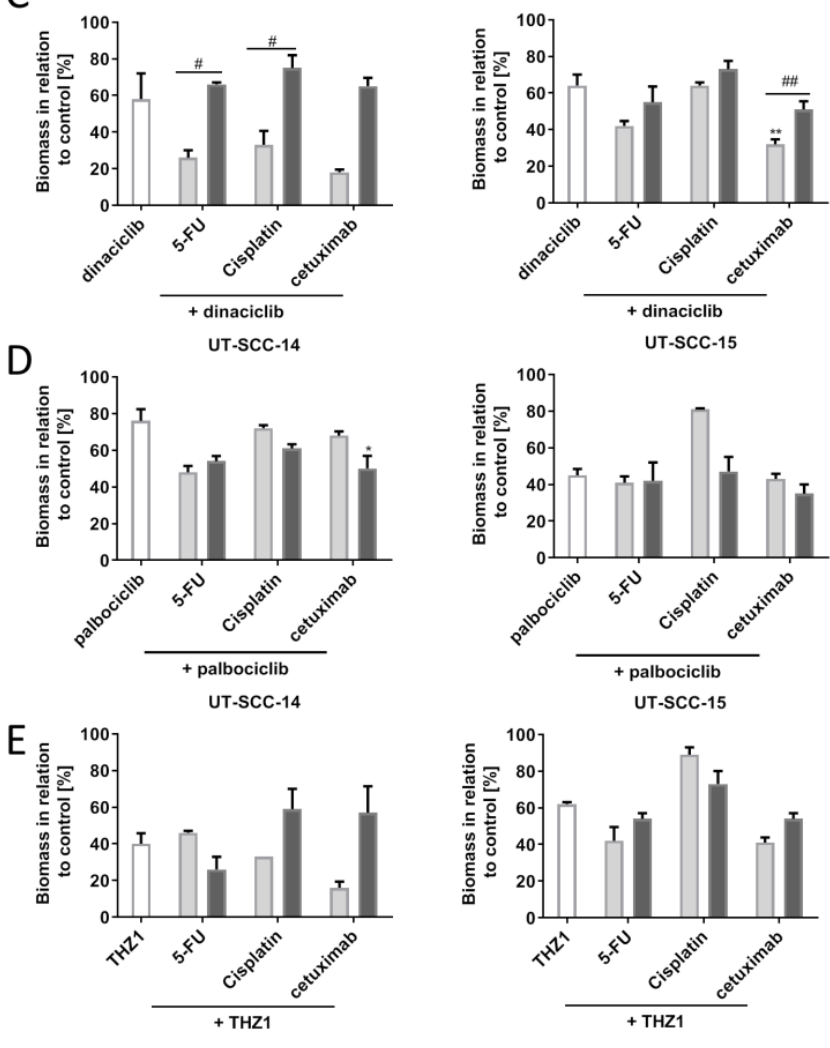

Standard $\rightarrow$ CDKi

CDKi $\rightarrow$ Standard

Figure 1. Simultaneous and sequential treatment schedules. (A) Biomass quantification after monotherapy with 5-FU, Cisplatin, and cetuximab $(1 \times 72 \mathrm{~h})$. Doses used here were determined before using classical dose response curve analysis. Read out was done by crystal violet staining and biomass in relation to untreated controls quantified. In (B) the Bliss Independence model was used to calculate potential synergistic effects. The green color indicates a synergistic and red color an antagonistic effect of the simultaneous combinations. (C-E) Sequential treatment: (C) dinaciclib [0.005 $\mu \mathrm{M}]$, (D) palbociclib $[1 \mu \mathrm{M}$ ], and (E) THZ1 [UT-SCC14: $0.02 \mu \mathrm{M}$; UT-SCC-15: $0.005 \mu \mathrm{M}$ ] in comparison to $2 \times 72 \mathrm{~h}$ CDKi monotherapy (first bar of each graph). Drug doses were as follows: 5-FU [0.32 $\mu \mathrm{g} / \mathrm{mL}]$; Cisplatin [UT-SCC14: $0.5 \mu \mathrm{g} / \mathrm{mL}$; UT-SCC-15: $0.05 \mu \mathrm{g} / \mathrm{mL}]$; cetuximab [0.5 $\mu \mathrm{g} / \mathrm{mL}$. Mann Whitney U-test $(n=3-4$ independent experiments) \# $p<0.05$, \#\# $p<0.01 \mathrm{vs}$. 1st CDKi; Kruskal Wallis test $\left(n=3-4\right.$ independent experiments) ${ }^{*} p<0.05,{ }^{* *} p<0.01$ vs. monotherapy. The $1 \times 72 \mathrm{~h}$ monotherapy with 5-FU, Cisplatin or Cetuximab confirms that the potential enhancing effect of sequential combination therapy is not due to the single administration of these substances but the effect of the $2 \times 72 \mathrm{~h}$ CDKi monotherapy (in the left bar) is actually enhanced.

In a first series, simultaneous combinations were applied (Figure 1B). Notably, dual CDKi treatment was synergistic or additive in UT-SCC-14 and partially in UT-SCC-15 cells as determined by biomass quantification. Here, combinations of dinaciclib with palbociclib or THZ1 were synergistic (Figure 1B). CDKi/drug combinations were mainly antagonistic. The only exception was seen for Cisplatin in conjunction with dinaciclib (UT-SCC-14) and cetuximab with dinaciclib or THZ1 (UT-SCC-15). 
To test if the effect of a $2 \times 72 \mathrm{~h}$ CDKi monotherapy can be boosted, sequential combinations were performed (Figure 1C-E). The first bar of each graph shows CDKi monotherapy, followed by the sequential combination treatments. CDKi were either given before or after standard therapy. The sequential treatment with dinaciclib (Figure 1C) revealed higher biomass reduction in both cell lines when standard therapy was given first. There was a strong reduction for all three combinations in UT-SCC-14 and UT-SCC-15. The sequential treatment with palbociclib yielded opposite results (Figure 1D). Here, palbociclib pretreatment prior to Cisplatin or cetuximab was better than the other way around. The order of 5-FU application had no leverage. For the sequential combination with THZ1 (Figure 1E), cell line-specific responses were seen. UT-SCC-14 cells' viability was more affected when 5-FU was given first and second THZ1. Comparable effects were seen after THZ1/Cisplatin treatment in UT-SCC-15 cells. Still, the other combinations were only effective when the standard drug was given before.

The aforementioned findings nicely confirm the heterogeneous response pattern of HNSCC.

\subsection{CDKi's Induce Apoptotic and Necrotic Cell Death and Mediate Calreticulin Translocation}

To investigate the effects of different treatments on the two cell lines, an apoptosisnecrosis assay was performed on selected treatment schedules (Figure 2A,B). Cells were simultaneously treated with CDKi's and drugs (5-FU, Cisplatin) for 24 and $72 \mathrm{~h}$ (Figure 2A,B). Short-term dinaciclib monotherapy mainly induced early apoptotic and necrotic cell death. The other monotherapies had minor or no impact on cell viability. After $72 \mathrm{~h}$, overall cell death was higher in treated cells, but with individual differences. Dinaciclib alone or in combination induced necrosis, THZ1 and its combinations triggered apoptosis or a mixed form of apoptosis and necrosis (Figure 2A,B). Additionally to the induced cell death, senescence was studied, since this is a common response to CDK inhibition (Figure S1). These experiments revealed senescence induction by specific CDKi's (e.g., dinaciclib) or its combination with standard drugs (e.g., 5-FU). However, senescence was not the dominating cellular response here, suggesting a minor role. UT-SCC-14 cells clumped together, especially under dinaciclib monotherapy and combination therapy, while UT-SCC-15 cell clusters were disrupted. The combination of THZ1 and 5-FU had similar effects to dinaciclib.

Then, the ability to induce immunogenic cell death was measured after $72 \mathrm{~h}$ by detecting calreticulin (CalR) on the tumor cells' surface (Figure 2C). The proportion of CalR positive cells and the mean fluorescence intensity signal (MFI) (Figure 2D) were recorded. Dinaciclib induced CalR translocation in monotherapy and combination therapy significantly. Notably, the combination of THZ1 and 5-FU likewise induced CalR translocation. While these findings already hint towards immune stimulating properties, we additionally checked for immunologically relevant markers (Figure 3A,B). The abundance of HLA-ABC (MHC class I) and PD-1 on tumor cells was examined. A significant increase in MHC class I was seen after dinaciclib monotherapy and combination therapy as well as upon palbociclib treatment of UT-SCC-14 cells (Figure 3A). The MHC class I abundance changed marginally in UT-SCC-15 cells irrespective of the treatment schedule used (Figure 3B). This was, however, likely because of the high basal MHC class I abundance, which was about $80 \%$. Still, dinaciclib and their combinations tended to upregulate MHC class I, finally yielding $\sim 100 \%$. PD-1 was upregulated by certain treatments. This did, however, not reach statistical significance (Figure 3A,B). 

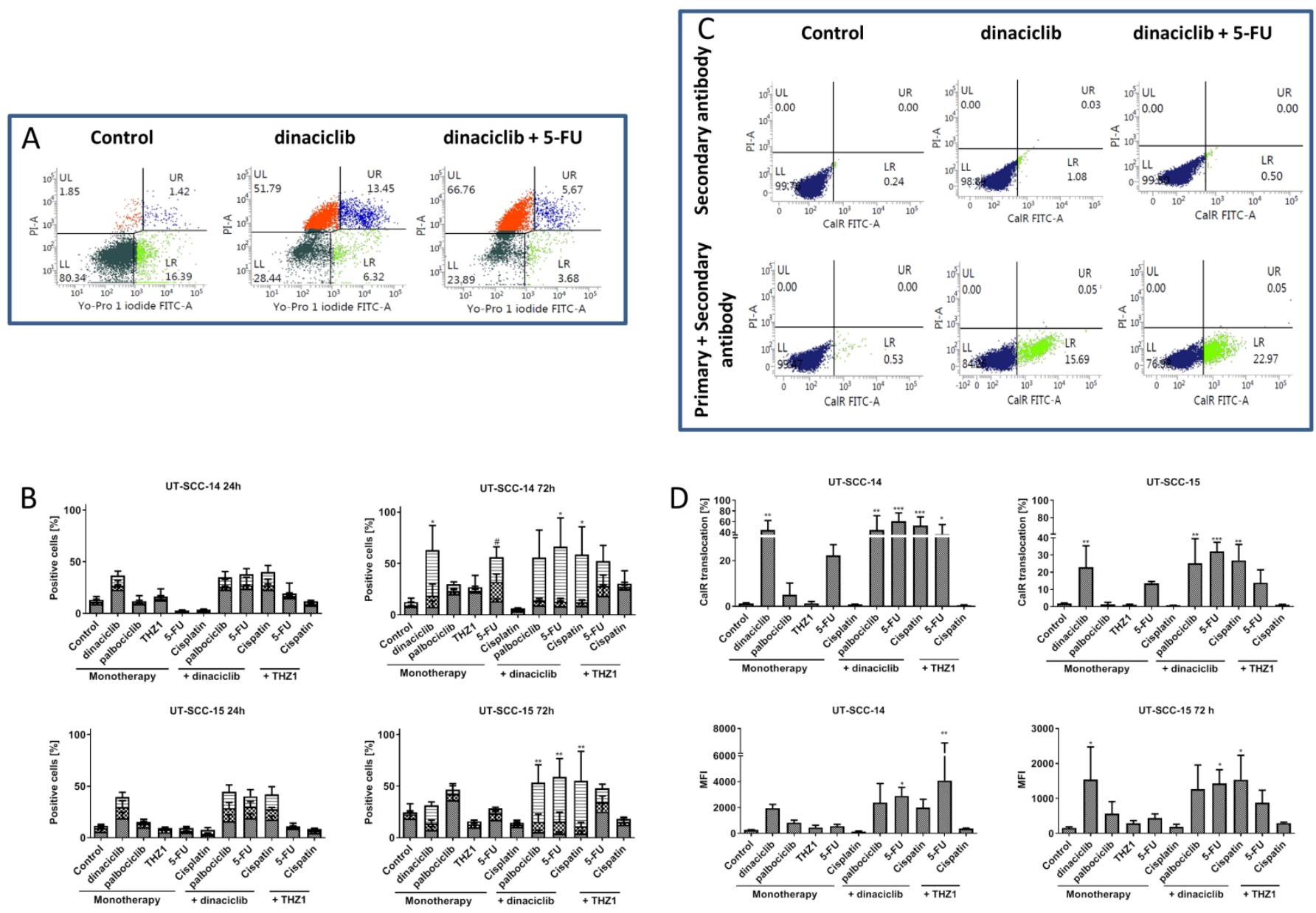

early apoptotic \#四 late apoptotic ${ }^{*} \boxminus$ necrotic

Figure 2. Apoptosis/necrosis assay and detection of immunogenic cell death (ICD). For (A,B) apoptosis/necrosis assay, cells were stained with Yo-Pro 1 iodide and PI. Cells that were positive for Yo-Pro 1 iodide were defined as early apoptotic, cells that were positive for PI were defined as necrotic, and double positive cells were defined as late apoptotic. Apoptosis/necrosis assay was done after $24 \mathrm{~h}$ and $72 \mathrm{~h}$. (A) Representative dots plots showing distribution of viable and dead cells (either apoptotic or necrotic). (B) Quantitative analysis of apoptotic and necrotic cells subdivided into early apoptotic $\left(\right.$ Yo-Pro1 $\left.^{+} / \mathrm{PI}^{-}\right)$, late apoptotic $\left(Y_{0}-\mathrm{Pro1}^{+} / \mathrm{PI}^{+}\right)$and necrotic $\left(\left(Y_{0}-\mathrm{Pro} 1^{-} / \mathrm{PI}^{+}\right)\right.$. (C,D)) ICD was detected after $72 \mathrm{~h}$ treatment by staining CalR on the cell surface. In both assays, 10,000 events were measured and the percentage of cells showing CalR translocation and the mean fluorescence intensity (MFI) of CalR ${ }^{+}$cells are provided. Drug doses were as follows: dinaciclib [0.02 $\mu \mathrm{M}$ ]; palbociclib [1 $\mu \mathrm{M}$ ]; THZ1 [UT-SCC14: $0.02 \mu \mathrm{M}$; UT-SCC-15: $0.005 \mu \mathrm{M}$ ]; 5-FU [90 $\mu \mathrm{g} / \mathrm{mL}$ ]; Cisplatin [0.1 $\mu \mathrm{g} / \mathrm{mL}]$. (B) Kruskal Wallis Test ( $n=4-5$ independent experiments); late apoptotic $\# p<0.05$ vs. control; necrotic ${ }^{*} p<0.05,{ }^{* *} p<0.01$ vs. control (D) 1way ANOVA ( $n=3-4$ independent experiments) ${ }^{*} p<0.05,{ }^{* *} p<0.01,{ }^{* * *} p<0.001$ vs. control. 
A

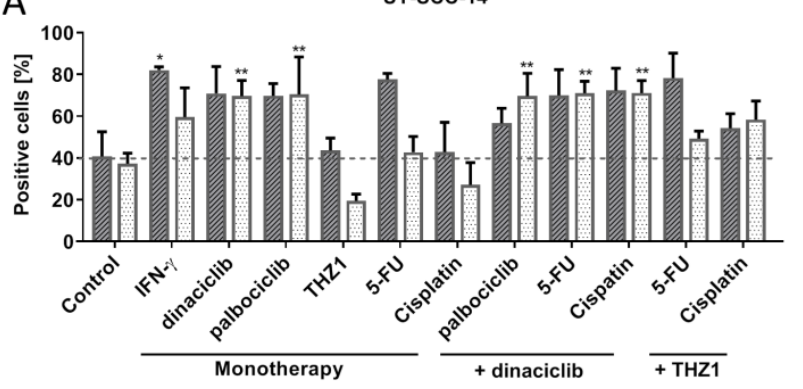

B

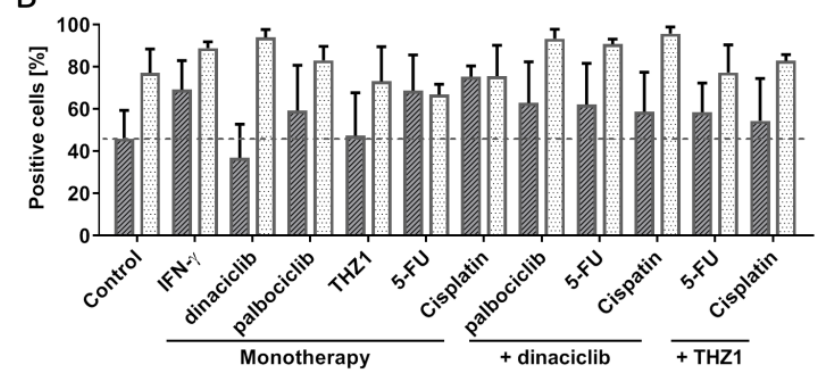

m PD1 $m$ HLA-ABC

C

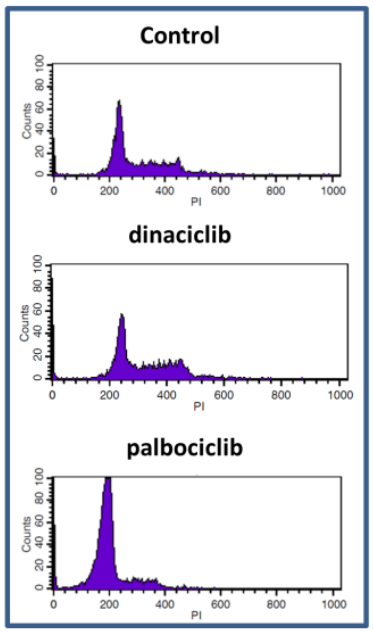

UT-SCC-14

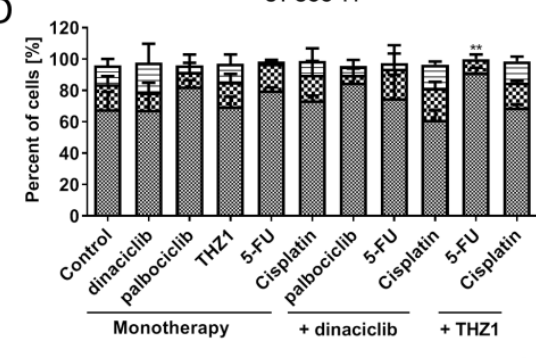

$E$

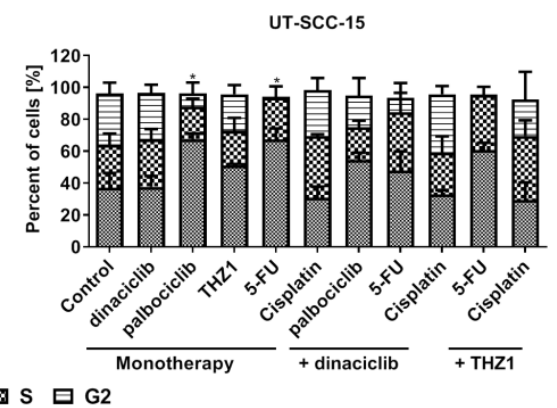

Figure 3. Phenotyping and cell cycle analysis. Phenotyping of (A) UT-SCC-14 and (B) UT-SCC-15 cells using multi-color flow cytometry. Therefore, cells were stained after $48 \mathrm{~h}$ treatment with test substances using the following antibodies: anti-HLA-ABC antibody (MHC I) and anti-CD279 (PD-1). Drug doses were as follows: IFN- $\gamma[50 \mathrm{ng} / \mathrm{mL}]$; dinaciclib

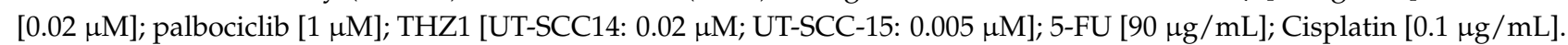
1 way ANOVA $\left(n \geq 3\right.$ independent experiments) $* p<0.05,{ }^{* *} p<0.01$, vs. control. (C-E) Cell cycle analysis. Ethanol-fixed cells were stained with PI. (C) Representative histograms showing distribution of cell cycle phases in control cells and upon therapy. (D,E) Quantitative cell cycle analysis showing amounts of cells in G1, S, and G2 phase. Drug doses were as follows:

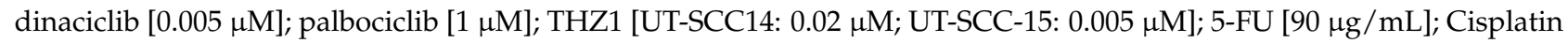
$[0.1 \mu \mathrm{g} / \mathrm{mL}]$. 1way ANOVA ( $n=3$ independent experiments) ${ }^{*} p<0.05,{ }^{* *} p<0.01$ vs. control.

\subsection{CDKi Induce Cell Cyclce Arrest}

Due to the mode of action of CDKi's, cell cycle analysis was done on residual tumor cells (typically below 50\%; Figure 3C-E). Representative histograms for all treatments are given in Figure S4. The number of residual cells after dinaciclib treatment was low. In these, tumor cells' cycle distribution was quite similar to controls. In UT-SCC-14 cells, a lucid G1 arrest was only seen after combined THZ1 and 5-FU therapy ( $p<0.05$ vs. control), while the remaining treatments had a minor impact on the cell cycle. UT-SCC-15 cells had significant changes after palbociclib and 5-FU monotherapy, but not in the combinations.

\subsection{CDKi's Have Minor Impact on Double-Strand Breaks and Radiosensitivity}

Treatment-induced double-strand breaks (DSBs) were determined by fluorescence microscopy using $\gamma-\mathrm{H} 2 \mathrm{AX}$ (Figure 4). H2AX is phosphorylated by kinases after DNA double-strand breaks on serine 139. CDKi monotherapy or combination therapy itself had minor impacts on $\gamma-\mathrm{H} 2 \mathrm{AX}$ foci, which were hardly detectable (Figure 4). To test if the applied regimens may enhance radiosensitivity, we then checked for irradiation-induced DSBs using 2 Gy (Figure 4B). Indeed, numbers of $\gamma$-H2AX-positive cells increased, with 
highest amounts in cells treated with palbociclib. With regard to the combinations, $\gamma$ H2AX foci were primarily seen in palbociclib-or THZ1- based combinations with 5-FU. By contrast, such radiosensitizing effects were not seen in combinations with dinaciclib and may thus constitute a specific consequence of palbociclib or THZ1 treatment.

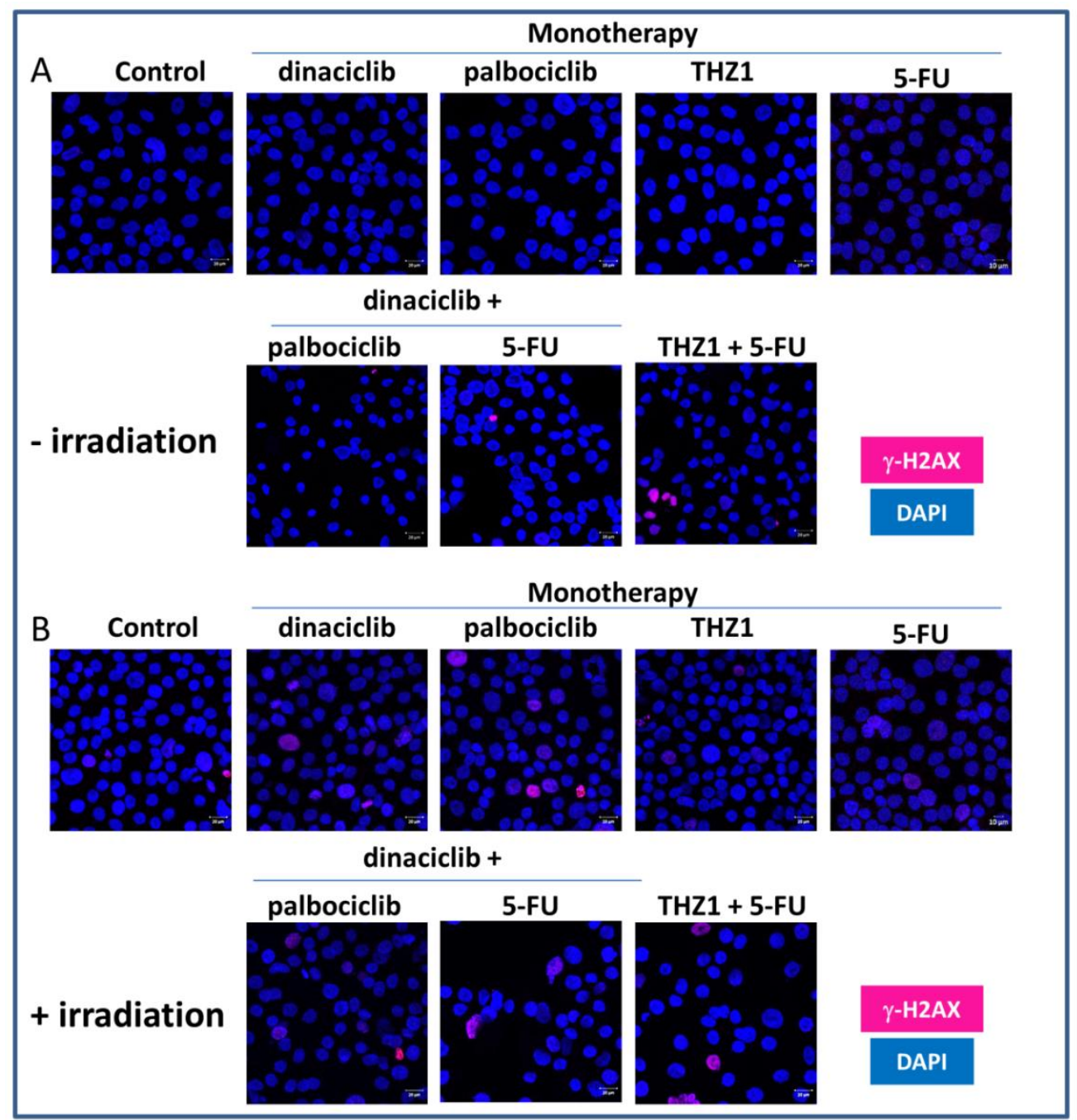

Figure 4. $\gamma-\mathrm{H} 2 \mathrm{AX}$ staining of UT-SCC-14 cells. In order to detect a potential radiosensitizing effect of the test substances, cells were treated $24 \mathrm{~h}$ with selected monotherapy and combination therapies and then irradiated with 2 Gy using an IBL637. (A,B) We had three control groups. The first was completely untreated, the second was treated with the test substances but not irradiated, and the third was only irradiated but not treated with the test substances. Drug doses were as follows: dinaciclib [0.005 $\mu \mathrm{M}$ ]; palbociclib [1 $\mu \mathrm{M}]$; THZ1 [0.02 $\mu \mathrm{M}]$; 5-FU [0.32 $\mu \mathrm{g} / \mathrm{mL}] ; \gamma-\mathrm{H} 2 \mathrm{AX}$ staining was performed $6 \mathrm{~h}$ after irradiation. Cell nuclei were stained with DAPI. Images were taken on a Zeiss LSM-780 Confocal Laser Microscope.

\subsection{CDKi's Remodel the Actin Filament}

Live cell monitoring via impedance measurements is particularly suitable for studying alterations in the cell monolayer, in the adhesion properties, and in the membrane integrity in real time. While the impedance increased over time in untreated control cells, dinaciclib treatment massively reduced impedance (Figure 5A,B). For palbociclib treated UT-SCC-14 cells, the measured impedance slightly decreased after $48 \mathrm{~h}$, while THZ1 monotherapy slightly increased impedance (Figure 5A). Notably, the combination of THZ1 and 5-FU caused a delayed impedance breakdown in both cell lines. Here, impedance increased 
within the first $20 \mathrm{~h}$. Thereafter, the impedance stagnated for approximately $3 \mathrm{~h}$, and then decreased for the next $48 \mathrm{~h}$ until no impedance was detectable. Dinaciclib in conjunction with cytostatics (Cisplatin, 5-FU) induced a complete and irreversible breakdown.
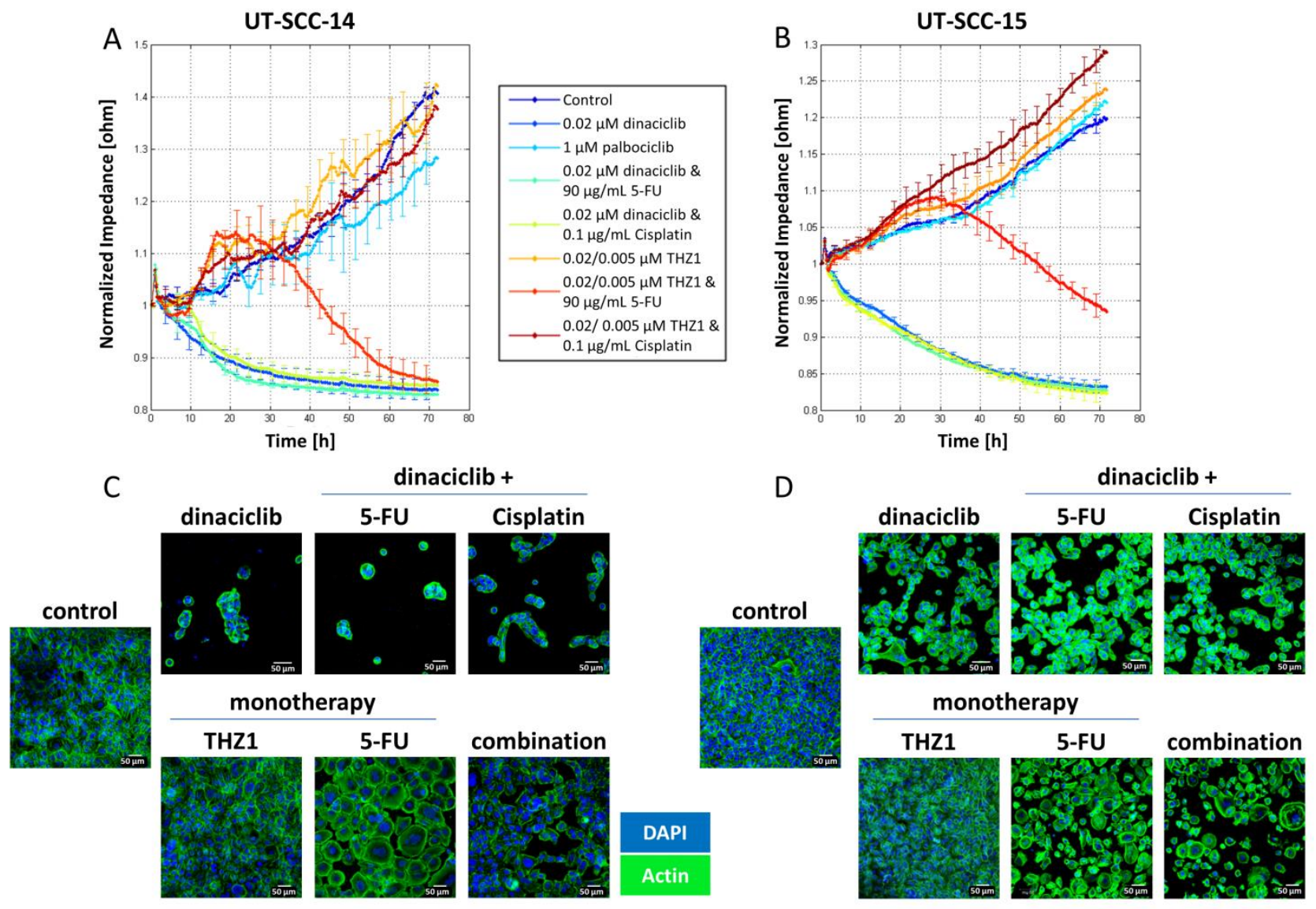

Figure 5. Impedance measurement and cytoskeletal staining. (A,C) UT-SCC-14 and (B,D) UT-SCC-15 cells. Cells were seeded in a 96-well ECIS array plate with 20 interdigitated electrodes/well and treated with selected test substances to investigate the impact of the treatment schedules. Drug doses were as follows: dinaciclib [0.02 $\mu \mathrm{M}] ;$ palbociclib [1 $\mu \mathrm{M}]$; THZ1 [UT-SCC14: $0.02 \mu \mathrm{M}$; UT-SCC-15: $0.005 \mu \mathrm{M}$ ]; 5-FU [90 $\mu \mathrm{g} / \mathrm{mL}$; Cisplatin [0.1 $\mu \mathrm{g} / \mathrm{mL}$ ]. Impedance was monitored in real-time. The analysis of cell-cell contacts was performed by $4000 \mathrm{kHz}$ using ECIS Software. Then, actin staining was performed with phalloidin green. Cell nuclei were stained with DAPI. Analysis was performed with a Zeiss LSM-780 Confocal Laser Microscope. Original magnification $200 \times$.

To confirm the impedance data, actin fibers were stained $72 \mathrm{~h}$ after treatment (Figure 5C,D). Untreated UT-SCC-14 cells form a typical monolayer with a cortically formed cytoskeleton and less stress fibers within the cells. Dinaciclib itself caused massive cell detachment and consequently cell death. Nearly all UT-SCC-14 cells were detached after dinaciclib treatment, while some UT-SCC-15 cells remained attached and spread. Cytostatics (Cisplatin, 5-FU) intensified actin abundance in both cell lines.

THZ1 strengthened the formation of stress fibers in both cell lines that increases cellular stiffness and changes the motility properties [20]. This finding adds to the higher impedance under THZ1 treatment compared to the untreated control. THZ1 in combination with 5-FU caused higher cytotoxic effects, so most cells were detached.

\subsection{Influence on Mitochondria, Lysosomes, the Endoplasmatic Reticulum and Vacuole Formation}

CDKi-based treatments induced cytoplasmic vacuole formation. Hence, we checked the influence of the treatment schedules on mitochondria, lysosomes, and endoplasmatic reticulum (ER) (Figure 6). In both cell lines, mitochondrial activity increased after dinaciclib 
monotherapy and combination therapy (Figure 6). Monotherapy with palbociclib, THZ1, or Cisplatin induced lysosome formation, but only in UT-SCC-14 cells. An effect of the treatments on the ER could not be demonstrated. After 5-FU treatment, the mitochondrial activity of UT-SCC-15 cells slightly increased that was reversed by THZ1. Cisplatin monotherapy had opposite effects that were neutralized by the combination partners (Figure 6B).

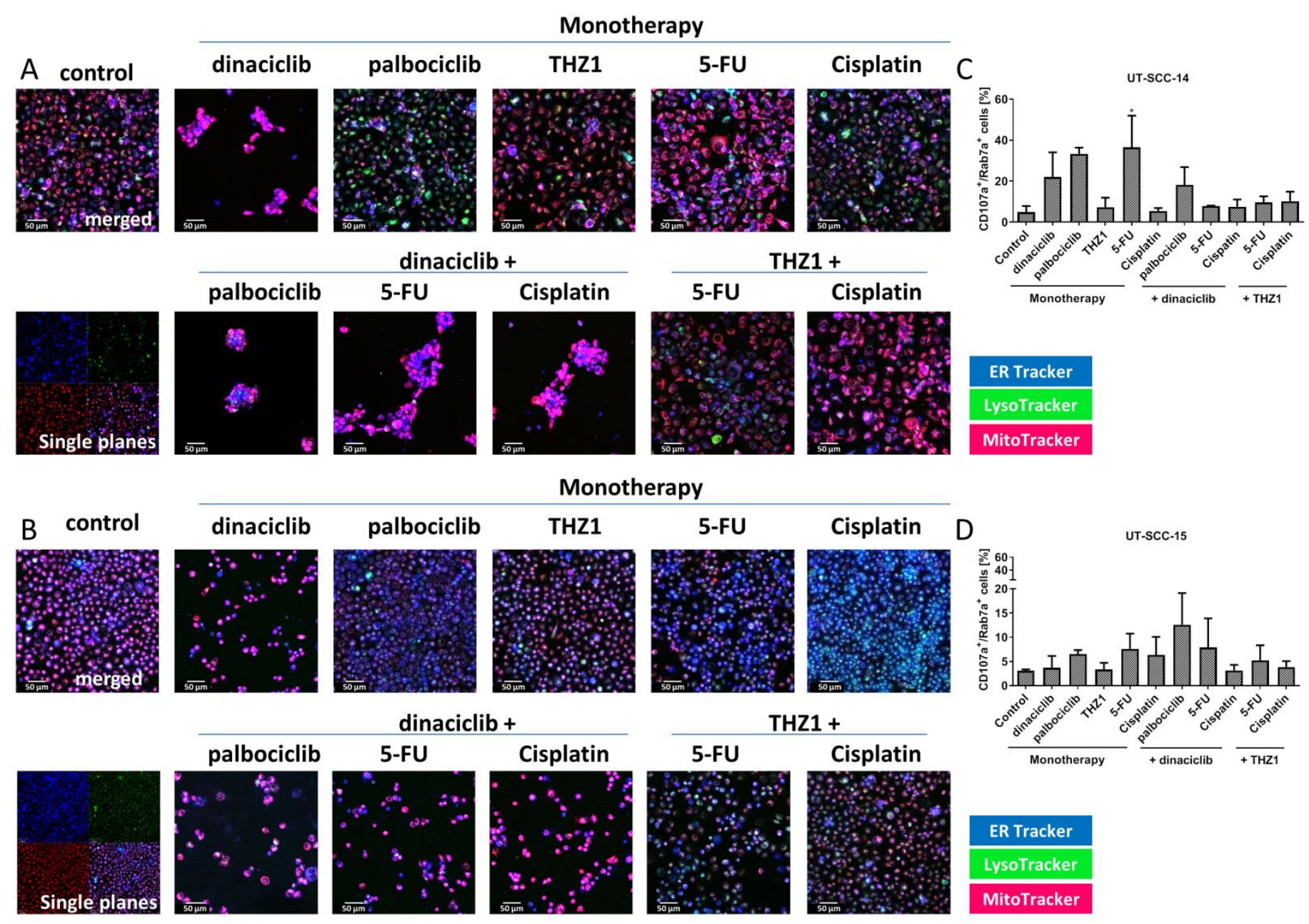

Figure 6. Influence on mitochondria, lysosomes, ER, and vacuole formation (A,C) UT-SCC-14 and (B,D) UT-SCC-15 cells. (A,C) To investigate the effect of the test substances on the mitochondrial activity, the lysosome formation, and the ER, cells were treated for $72 \mathrm{~h}$ with test substances and stained with MitoTracker (red), LysoTracker (green), and ER-Tracker (blue). Drug doses were as follows: dinaciclib [0.02 $\mu \mathrm{M}$ ]; palbociclib [1 $\mu \mathrm{M}$ ]; THZ1 [UT-SCC14: $0.02 \mu \mathrm{M}$; UT-SCC-15: 0.005 $\mu \mathrm{M}$ ]; 5-FU [90 $\mu \mathrm{g} / \mathrm{mL}]$; Cisplatin [0.1 $\mu \mathrm{g} / \mathrm{mL}$ ]. Representative merged images are shown. For the control, a separated fluorescent image is shown. Analysis was performed with a ZEISS Elyra 7 Confocal Laser Microscope. (C,D) Cells were stained for CD107a and Rab7a as a hint for vacuole formation and measured via flow cytometry. The percentage numbers of double positive cells are shown. Drug doses were as follows: dinaciclib [0.02 $\mu \mathrm{M}]$; palbociclib [1 $\mu \mathrm{M}]$; THZ1 [UT-SCC14: $0.02 \mu \mathrm{M}$; UT-SCC-15: $0.005 \mu \mathrm{M}]$; 5-FU [90 $\mu \mathrm{g} / \mathrm{mL}]$; Cisplatin $[0.1 \mu \mathrm{g} / \mathrm{mL}]$. 1way ANOVA $(n=3$ independent experiments $) * p<0.05$ vs. control.

Cells were stained for specific late endo-lysosomal markers CD107a (LAMP1) and Rab7a to confirm above findings (Figure 6C,D). The GTPase Rab7a is primarily associated with late endosomes and LAMP1 is typically considered lysosomal [21]. Cell line specific responses were observed, with UT-SCC-14 cells showing higher numbers of these late endo-lysosomal markers after treatment. In detail, dinaciclib, palbociclib, and 5-FU monotherapy resulted in the highest increase of positive cells ( $p<0.055-\mathrm{FU}$ vs. control) 
(Figure 6C). The combinations could not boost effects. In UT-SCC-15 cells, highest numbers of CD107a $\mathrm{a}^{+} / \mathrm{Rab}^{+} \mathrm{a}^{+}$cells were detected after dual CDK inhibition (palbociclib + dinaciclib) (Figure 6D), implying that lysosomal formation plays a minor role here.

\subsubsection{CDKi's Reduce Invasiveness and Migratory Potential}

An assay was performed to explore the migration potential of cells to a cell free space under treatment. The cell line UT-SCC-14 filled the scratch within $24 \mathrm{~h}$; the same was true for THZ1 and 5-FU monotherapy and combination therapy (Figure S2A). The toxic activity of dinaciclib induced cell death within $72 \mathrm{~h}$ and an accordingly incomplete scratch closure. Adding THZ1 to dinaciclib delayed migration, so the scratch was filled after $48 \mathrm{~h}$. Using an invasion assay, the ability of cells to escape from the toxic environment was then investigated. For this experiment, selective treatments were included based on the obtained results shown before. The invasive cells from treatment medium were put in relation to invasive cells from control medium. CDKi treatment with dinaciclib significantly reduced invasiveness (Figure S2B). Effects were even stronger when two CDKi's were combined (dinaciclib + THZ1), but not by adding 5-FU. Still, these data confirm the potential of CDKi's to interfere with cellular invasion.

\subsubsection{In Vivo Results}

Finally, a xenograft mouse model was used to test if in vitro results can be transferred in vivo. For this proof-of-concept study, dinaciclib and Cisplatin were chosen as therapeutics and given alone or in combination (Figure 7A). We decided to use this combination, since dinaciclib had strong antitumoral effects in all previous analyses and Cisplatin is the accepted standard of care for HNSCC patients.

UT-SCC-14 xenografts showed a poor treatment response. Monotherapy had no influence on tumor growth and the combination was only able to decelerate growth (Figure 7B). In contrast, UT-SCC-15 xenograft growth was significantly reduced under therapy (Figure 7B). Dinaciclib and its combination with Cisplatin decreased the tumor volume to a minimum, the latter even stopped tumor growth until the experimental endpoint (two months follow-up). As a consequence of the better treatment response, mice challenged with UT-SCC-15 lived longer compared to those harboring UT-SCC-14 xenografts (Figure 7C). The outcome was best in the combination with a median survival of 63 days (vs. control 42 days, $p<0.05$ ). As for dinaciclib monotherapy, mice had to be euthanized mostly because of tumor ulcerations. Hence, the poorer survival in both cases is not justified by the tumor volume as an endpoint but due to ethical aspects. Histology of residual tumors confirmed the different treatment responses. UT-SCC-14 xenografts presented with initial necrosis that increased after dinaciclib treatment (Figure 7D). After Cisplatin therapy, beginning necrosis with initial inflammatory reaction was visible, but also vital tumor tissue. In the combination, keratinized squamous cell carcinoma containing degenerated cells was found. In addition, neutrophilic infiltration was observed. The UT-SCC-15 xenograft sections of control mice showed characteristics of a keratinizing squamous cell carcinoma with developing necrosis. After dinaciclib treatment, degenerated and early apoptotic cells became prominent with surrounding necrosis. Cisplatin monotherapy primarily induced necrosis. The dark spot in the center of the image is degenerated keratinized squamous epithelium. Necrosis was dominating in the combination with some swollen cells, indicative of early cell damage in the initial stage. 


\begin{tabular}{|c|c|}
\hline Test substance & Treatment schedule \\
\hline Control & 3 \% DMSO i.p., q3wx6 \\
\hline dinaciclib & $20 \mathrm{mg} / \mathrm{kg}$ bw, i.p., q3wx6 \\
\hline Cisplatin & 6 mg/kg bw, i.p., q1wx4 \\
\hline Combination & $\begin{array}{l}20 \mathrm{mg} / \mathrm{kg} \text { bw, i.p., q3wx6 } \\
6 \mathrm{mg} / \mathrm{kg} \text { bw, i.p., g1wx4 }\end{array}$ \\
\hline
\end{tabular}
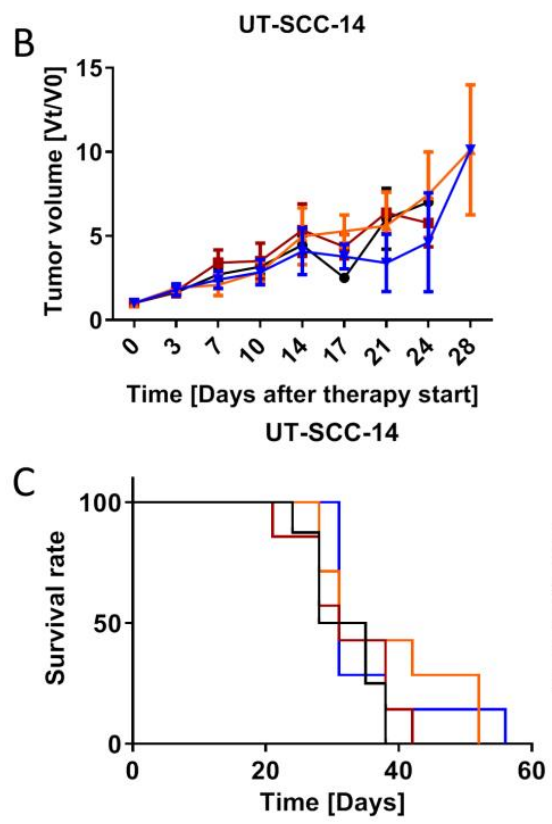

- Control - dinaciclib $20 \mathrm{mg} / \mathrm{kg} \mathrm{BW}+$ Cisplatin $6 \mathrm{mg} / \mathrm{kg} \mathrm{BW}+$ Combination
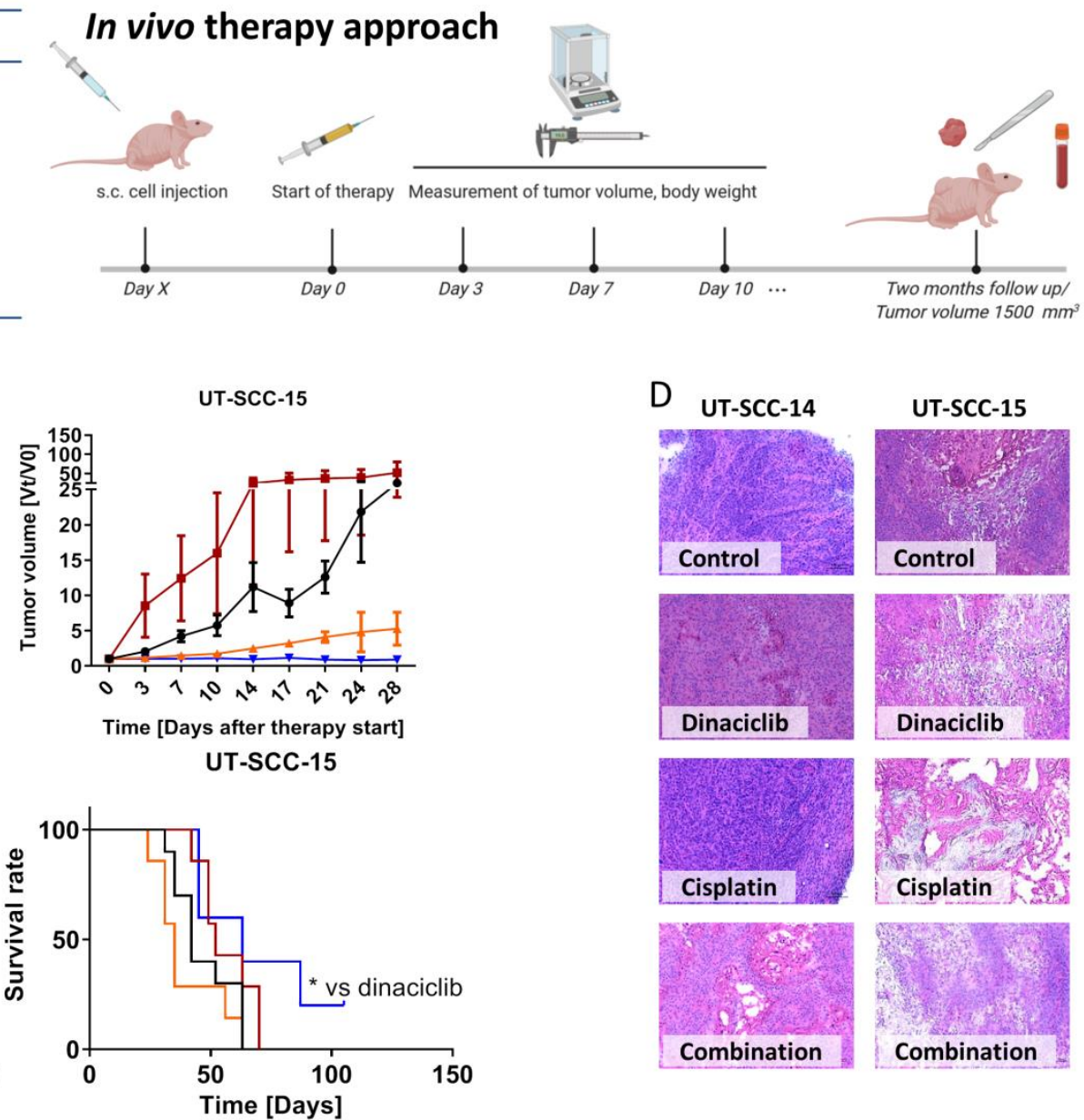

Dinaciclib

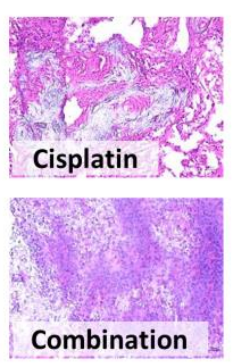

Figure 7. In vivo therapy approach. (A) Schematic overview over the treatment protocol with given doses of the test substances. (B) Tumor growth curve. Tumor volume was calculated as tumor volume at day $\times(\mathrm{Vt})$ divided through the tumor volume at the therapy start (V0). (C) Kaplan-Meier survival curve and Log-rank (Mantel-Cox) test. UTSCC-14: control ( $n=8$ mice); Cisplatin/dinaciclib/combination ( $n=7$ mice/group); UT-SCC-15: control ( $n=10$ mice); Cisplatin/dinaciclib ( $n=7$ mice/group); combination ( $n=5$ mice); $p<0.05$ vs. dinaciclib. (D) Representative images of the HE stained tumors of each treatment group. Magnification $20 \times$, Scale bar.

\section{Discussion}

CDKi's are being applied in clinical trials to treat solid and hematological malignancies (e.g., NCT04169074, NCT04391595, NCT03981614, and NCT01627054). For locally advanced or metastatic breast cancer, the CDK4/ 6 inhibitors palbociclib, ribociclib, and abemaciclib are FDA approved in combination with endocrine therapy [22,23]. Though approval for HNSCC is still pending, first preclinical and clinical reports are promising $[16,24,25]$.

Our study adds another piece of evidence and identifies the CDK4/ 6 inhibitor palbociclib as well as the global acting CDKi's dinaciclib and THZ1 as promising candidates for HNSCC treatment. We additionally describe the strong dependency on (a) the combination partner and (b) the temporal order of applying each substance to reach therapeutic effects. Notably, simultaneous dual CDKi treatment, but not the combination with standard drugs, worked synergistically in our settings. The sequential application yielded heterogeneous results, depending on the CDKi used for combination. In theory, chemotherapeutic drugs should benefit from prior CDKi treatment by completing their effects [26,27]. However, this was only seen here when the CDK4/ 6 inhibitor palbociclib was used as first treatment, confirming findings from a recent study in which intrinsic resistance was reported when 
Cisplatin was given before palbociclib because of drug-induced c-Myc and Cyclin E upregulation [19]. Though not analyzed in detail here, comparable molecular alterations can be anticipated. Besides direct antitumoral effects, another argument for applying specific CDKi's in the first-line is the protection of normal hematopoietic stem and progenitor cells via transient $\mathrm{G} 1$ cell cycle arrest induction and the maintenance of antitumor immunity to boost the patient's tolerability towards chemotherapy [28]. This "positive" side effect was recently observed in phase II trials on patients with small-cell lung cancer receiving the CDK4/ 6 inhibitor trilaciclib $[28,29]$. Hence, a favorable outcome can indeed be speculated if CDK4/ 6 inhibitors are applied in the first-line. For the more global acting CDKi's, such beneficial responses are very unlikely. Instead, leukopenia and neutropenia were reported as direct consequences of the complex mode of action, including interference with RNA polymerase II binding [30-32]. These systemic toxicities constitute a major limitation and clinicians will have to cope with this challenge. With regard to the sequential application applied here, first-line chemotherapy was superior to second-line chemotherapy. This regimen was comparable to or even better than two cycles of dinaciclib or THZ1 monotherapy. Mechanistically, effects were due to early apoptosis with a shift to necrosis afterward. Quite in line with this, Hossain et al. also observed apoptosis induction by short-term dinaciclib treatment [33]. Notably, THZ1, had a minor impact on apoptosis, though this was described in literature in an $\mathrm{nM}$ range and thus was comparable to doses used here [34]. This might be best explained by some kind of delayed apoptosis induction but not intrinsic apoptosis resistance of our HNSCC cells. In support of this, the specific CDK4/6 inhibitor palbociclib triggered apoptosis in both cell lines, confirming recent observations [35]. Senescence, another CDKi-induced cellular stress response, was also seen here; however, it was not as profound as described in the literature [36]. Hence, senescence may either play a minor role in HNSCC or it was an early event and thus undetectable after two rounds of treatment. The strong cytotoxicity of dinaciclib and certain $\mathrm{CDKi} /$ drug combinations argue in favor of the latter.

Quite in line with this, impedance reduced massively under dinaciclib monotherapy and combination therapy that was accompanied by remarkable changes in cell shape and cytoskeletal organization. This, in turn, may impair cell-cell contacts via adhesion molecules, electrical coupling, and passage through gap junctions [37]. A comparable, but delayed impedance breakdown was achieved when THZ1 was combined with 5-FU, likely because of the 5-FU's mechanism of action [38]. Such a delayed effect under 5-FU treatment was also seen in the wound healing assay. Conversely, THZ1 monotherapy slightly increased impedance, accompanied by re-organization of cortical actin into stress fibers. These stress fibers increase the cellular stiffness and reduce the motility $[20,39,40]$. We therefore propose the identified shift in actin organization as main response towards drugs applied in this study that has to be addressed in more detail prospectively. By performing a direct comparison of the two cell culture models used here, it is obvious that the cell line UT-SCC-15, established from a nodal recurrence of a primary tongue carcinoma [41], shows more cortical actin than intracellular stress fibers. In the UT-SCC-14 cells, it is exactly the other way around. The cortical actin filaments are important to create tension, leading to gradients that generate changes in the shape which are important during cell migration, cell division, and tissue morphogenesis [42]. Also, we hypothesize that the remodeling of the actin filament makes the cells more vulnerable to immune cells. A prerequisite-among others-for this is the induction of immunogenic cell death (ICD) in tumor cells to activate phagocytes $[33,43,44]$. Actually, we observed increased Calreticulin (CalR) translocation upon combined THZ1/5-FU treatment. While this effect was not visible under monotherapy, we suggest this treatment regimen as a promising strategy for immunotherapeutic approaches. Notably, dinaciclib was similarly able to induce CalR translocation and upregulation of the immunologically relevant marker MHC class I to an extent comparable to THZ1/5-FU combination therapy. This makes dinaciclib particularly interesting in the context of immunotherapy, as hypothesized before $[33,45]$. Hossain et al. treated murine CT26 colon cancer cells for $24 \mathrm{~h}$ with different dinaciclib 
concentrations $(0.05 \mu \mathrm{M}-25 \mu \mathrm{M})$ and identified a linear increase in CalR translocation. The readout in this study was the mean fluorescence intensity, which was around 1200 after treatment with $0.05 \mu \mathrm{M}$ dinaciclib [33]. In our work, a concentration of $0.02 \mu \mathrm{M}$ dinaciclib yielded an MFI around 2000 for UT-SCC-14 and an MFI of around 1500 for UT-SCC-15 cells. Though the MFI is not directly comparable among different studies, it still confirms previous findings. Additionally to this, the observed upregulation of MHC class I enhances antigen presentation and ultimately stimulates $\mathrm{CD}^{+}-\mathrm{T}$-cells to finally promote antitumor immunity [46].

Radiotherapy is the mainstay of therapy for HNSCC patients and can be combined with immunotherapy. While radiotherapy itself has the potential to reprogram the tumor microenvironment, several drugs including CDKi's have been identified as radiosensitizers $[24,47,48]$. However, the CDKi's used here had a minor impact on double-strand breaks and radiosensitivity. Radiosensitization, if any, was seen after combining palbociclib or THZ1 with 5-FU. Wang et al. reported palbociclib-induced DNA damage in an p53-independent manner and repressed DNA damage repair ability via RAD51 downregulation [35]. THZ1 inhibits CDK7, CDK12, and CDK13 [49] and was described as radiosensitizer in a study on medulloblastomas [50]. Genes involved in homologous recombination such as Brca2, Rad51, and Rad50 were downregulated, accompanied by increased $\gamma \mathrm{H} 2 \mathrm{AX}$-foci post irradiation [50]. Another study likewise confirmed increased amounts of $\gamma-\mathrm{H} 2 \mathrm{AX}$ foci upon THZ1 treatment [51]. Hence, THZ1 has the potential to sensitize to radiation and impair recovery from radiation-induced DNA damage. The fact that another target of THZ1, CDK12, selectively controls the expression of genes involved in the DNA damage response, supports this theory [52]. The question remains why such effects were undetectable in our study. Apart from the radiation dose (2Gy), the time is a critical factor for detecting or missing a clear radiation response. Hence, it is conceivable that we have simply missed certain effects.

Another common response towards CDKi treatment is cell cycle alteration. Palbociclib induced a G1 phase arrest that complies with its mode of action and has been described in the literature [53-55]. Combined THZ1 and 5-FU therapy yielded comparable results in both cell lines that can be explained as follows: 5-FU limits the availability of thymidylate and inhibits the DNA synthesis [56,57]. THZ1 impairs CDK2 activity via inhibition of CDK7 $[58,59]$. CDK2 is required for the transition from G1 to $S$ phase, blocking this CDK thus holds the cell cycle [49]. This has profound biological effects. In a very recent study on patient-derived glioblastoma models, we described the CDKi-induced loss of mitochondrial function in pioneering work, characterized by a multivacuolar phenotype and signs of early-methuosis [60]. Methuosis, a non-apoptotic cell death phenotype, is defined by the accumulation of large fluid-filled cytoplasmic vacuoles that originate from macropinosomes [61]. With regard to the HNSCC cells used here, dinaciclib monotherapy and combination therapy strengthened the mitochondrial activity. However, methuosis did not seem to play a major role, as late endosomes and vacuoles markers CD107a and Rab7a exclusively increased under CDKi or 5-FU monotherapy. Hence, CDKi's have indeed different effects on individual tumor cells.

In a final in vivo proof-of-concept experiment, dinaciclib and Cisplatin were chosen based on the following criteria: Dinaciclib has complex effects on HNSCC tumor cells, including growth inhibition, prevention of migration/invasion, and cytotoxicity. Besides, dinaciclib is a potent ICD inducer and a promising candidate for combined immunotherapies. Cisplatin is a well-known cytostatic drug approved as 1st line HNSCC treatment and widely applied in the clinic $[11,62,63]$. Additionally, preclinical reports on combined dinaciclib-Cisplatin application are promising, as recently shown for a subcutaneous ovarian cancer xenograft model in nude mice [64]. Here, the combination approach was likewise superior to either single treatment and most effective in suppressing UT-SCC-15 growth. While this cell line was established from a nodal recurrence, it is tempting to speculate that advanced tumors may even benefit more from this regimen than lower-stage tumors. However, this has to be tested on a larger series of (matched) tumor samples. However, the 
accelerated growth of UT-SCC-15 xenografts under Cisplatin monotherapy is worth mentioning. Intrinsic resistance is unlikely, since these cells showed good sensitivity in vitro. Also, acquired resistance can be excluded because tumors grew constantly under treatment. Comparable effects were not reported in the literature. We can therefore only assume that outcomes may be improved by changing the treatment schedule (i.e., dose, application route, and the number of injections). Still, the complex interaction of tumor, normal stromal, and immune cells influences outcomes-a major contributing factor that can only partially be considered in vitro [65].

To sum up these findings, we provide another piece of evidence for the therapeutic activity of CDKi's, their complex mode of action, and the rationale to combine targeted agents with "conventional" drugs or even immune-restoring approaches to succeed in the long run.

\section{Materials and Methods}

\subsection{Tumor Cell Lines and Culture Conditions}

Two patient-derived cell lines: UT-SCC-14 and UT-SCC-15, were used. The UT-SCC-14 was established from a primary tumor of the tongue and the UT-SCC-15 derived from a nodal recurrence of the same origin. Both cell lines are HPV negative. Cells were maintained in full medium: DMEM/HamsF12 supplemented with $10 \%$ fetal calf serum (FCS), glutamine ( $2 \mathrm{mmol} / \mathrm{L}$ ) and antibiotics (medium and antibiotics were purchased from Pan Biotech, Aidenbach, Germany, FCS from Sigma-Aldrich, Darmstadt, Germany and glutamine from Biochrom, Berlin, Germany) and kept in low passages.

\subsection{Cytostatic Drugs and Targeted Substances}

The approved cytostatic drugs 5-FU $(50 \mathrm{mg} / \mathrm{mL})$ and Cisplatin $(1 \mathrm{mg} / \mathrm{mL})$, the approved therapeutic antibody cetuximab $(5 \mathrm{mg} / \mathrm{mL})$ and the targeted substances dinaciclib, palbociclib, and THZ1 (all $10 \mathrm{mM}$ ) were used. 5-FU, Cisplatin and cetuximab were purchased from the pharmacy of the University Hospital Rostock, dinaciclib and palbociclib from Selleckchem, Munich, Germany, and THZ1 from Hycultec, Beutelsbach, Germany.

\subsection{Dose Response Curves and Combination Therapy}

For dose response curves, cells were seeded in 96 well plates in three technical replicates per cell line and incubated for $24 \mathrm{~h}$ at $37{ }^{\circ} \mathrm{C}$ and $5 \% \mathrm{CO}_{2}$. Afterwards, cells were treated for $2 \times 72 \mathrm{~h}$ in monotherapy with the different test substances in concentrations ranging between $0.05 \mu \mathrm{g} / \mathrm{mL}$ and $1 \mathrm{mg} / \mathrm{mL}$ for approved drugs and $1 \mathrm{nM}$ and $1 \mu \mathrm{M}$ for CDKi's. Thereafter, various combinations were tested in simultaneous and sequential settings. Doses used for combinations were as follows: 5-FU [0.32 $\mu \mathrm{g} / \mathrm{mL}$ or $90 \mu \mathrm{g} / \mathrm{mL}$, Cisplatin $[0.05 \mu \mathrm{g} / \mathrm{mL}, 0.5 \mu \mathrm{g} / \mathrm{mL}$, or $0.1 \mu \mathrm{g} / \mathrm{mL}$, cetuximab $[0.5 \mu \mathrm{g} / \mathrm{mL}]$, dinaciclib [0.005 $\mu \mathrm{M}$ or $0.02 \mu \mathrm{M}]$, palbociclib [1 $\mu \mathrm{M}]$, and THZ1 [0.02 $\mu \mathrm{M}$ or $0.005 \mu \mathrm{M}]$ depending on the treatment duration of each substance $(1 \times 72 \mathrm{~h}$ or $2 \times 72 \mathrm{~h})$. Readout was done by crystal violet staining. In sequential combination therapy, two different approaches were applied. Firstly, the cells were treated with the standard therapy for $72 \mathrm{~h}$ and the CDKi's afterwards, and secondly, the administration was done in reverse order. To rule out the possibility that the single 72 -h administration of the approved therapeutics is responsible for the potentially stronger effect, they were tested in monotherapy for $72 \mathrm{~h}$. Potential synergistic or additive effects between the substances in a $2 \times 72 \mathrm{~h}$ simultaneous combination approach were analyzed with the Bliss Independence model.

\section{4. $\gamma$-H2AX Staining}

Tumor cells were treated for $24 \mathrm{~h}$ in Chamber Slides with selected concentrations and combinations of the test substances and then irradiated with 2 Gy (Cs-137 $\gamma$-irradiation; IBL 637, CIS Bio-International, Codolet, France). $\gamma$-H2AX staining was performed $6 \mathrm{~h}$ after irradiation. Cells were washed with phosphate-buffered saline (PBS), fixed in $4 \%$ paraformaldehyde w/o methanol (Thermo Scientific, Darmstadt, Germany) for 30 min, 
washed again, followed by cell permeabilization in 0.5\% Triton X-100 (Sigma-Aldrich, Darmstadt, Germany) for $15 \mathrm{~min}$. After blocking the unspecific binding sites with $1 \%$ bovine serum albumin (Serva, Heidelberg, Germany), cells were incubated with the monoclonal $\gamma$-H2AX antibody (1:100; BioLegend, San Diego, CA, USA) over night at $4{ }^{\circ} \mathrm{C}$. Cells were washed and nuclei stained with $4^{\prime}, 6$-diamidino-2-phenylindole (DAPI) (AAT Bioquest, Sunnyvale, CA, USA). Analysis was performed with a ZEISS Elyra 7 Confocal Laser Microscope (Zeiss, Jena, Germany).

\subsection{Apoptosis-Necrosis Assay, Phenotyping, and Immunogenic Cell Death}

Apoptosis-necrosis was determined after 24 and $72 \mathrm{~h}$ treatment, phenotyping was done after $48 \mathrm{~h}$, and determination of immunogenic cell death (ICD) was recorded after $72 \mathrm{~h}$ treatment. Cells were analyzed on a Flow Cytometer (BD FACSVerse ${ }^{\mathrm{TM}}$, BD Pharmingen, San Jose, CA, USA). Data analysis was done using the BD FACSuite software (BD Pharmingen).

For Apoptosis-necrosis, cells were stained for $20 \mathrm{~min}$ at room temperature with $0.2 \mu \mathrm{M}$ Yo-Pro 1 iodide (Thermo Scientific, Ex/Em 491/509 nm; blue laser $488 \mathrm{~nm}$ ) and $20 \mu \mathrm{g} / \mathrm{mL}$ Propidiumiodide (PI) (Sigma-Aldrich, Darmstadt, Germany; Ex/Em: 535/617 nm; blue laser $488 \mathrm{~nm}$ ). PI was added shortly before flow cytometry. For phenotyping, cells were stained for $30 \mathrm{~min}$ at $4{ }^{\circ} \mathrm{C}$ with FITC anti-HLA-ABC antibody (MHC I) (1:50; ImmunoTools, Friesoythe, Germany) and APC anti-CD279 (PD-1) (1:50; both from BioLegend, blue $(488 \mathrm{~nm})$ and red $(633 \mathrm{~nm})$ laser). ICD was detected by staining translocated CalR on the cell surface. Cells were incubated for $30 \mathrm{~min}$ at $4{ }^{\circ} \mathrm{C}$ with the polyclonal rabbit CalR primary antibody (1:50; Abgent, San Diego, CA, USA). Cells were washed and labeled with FITC-conjugated secondary antibody (donkey anti rabbit, 1:50; BioLegend), and incubated again for $30 \mathrm{~min}$ at $4{ }^{\circ} \mathrm{C}$. In order to exclude non-specific binding of the FITC-labeled secondary antibody, control cells were additionally stained with the secondary antibody without using the primary antibody. For CalR quantification, the number of cells that were positive for the secondary antibody was subtracted from the CalR+ secondary antibody stained cells.

\subsection{Cell Cycle Assay}

Cell cycle was determined after $48 \mathrm{~h}$ of treatment. Cells were harvested, counted, and resuspended with $1 \mathrm{~mL}$ ice cold $70 \%$ ethanol. Cells were incubated overnight at $-20{ }^{\circ} \mathrm{C}$, washed again, and incubated with $0.5 \mathrm{~mL} 0.25 \%$ TritonX-100 for $15 \mathrm{~min}$ on ice. Cells were washed and resuspended in RNAse A $(100 \mu \mathrm{g} / \mathrm{mL})$, supplemented with PI $(20 \mu \mathrm{g} / \mathrm{mL})$. After 30 min incubation on ice, cells were analyzed on a Flow Cytometer (FACSCalibur, BD, San Jose, CA, USA). Data analysis was done using BD FlowJo software (BD Pharmingen, San Diego, CA, USA).

\subsection{Influence on Mitochondria, Lysosomes, ER, and Vacuole Formation}

The influence on mitochondria, lysosomes, and the ER was examined with immunofluorescence staining. Cells were seeded in Chamber Slides and stained after $72 \mathrm{~h}$ treatment. Then, cells were washed and the staining with MitoTracker Red CMXRos (20 nM, CellSignaling Technology, Danvers, MA, USA) and ER-Tracker Blue-White DPX (1 $\mu \mathrm{M}$, Invitrogen) was done simultaneously for $35 \mathrm{~min}$ at $37^{\circ} \mathrm{C}$. Cells were washed and stained with LysoTracker DND-26 (50 nM, CellSignaling Technology) for $2 \mathrm{~min}$ at room temperature. Analysis was performed on a ZEISS Elyra 7 Confocal Laser Microscope (Zeiss).

Additionally, vacuole formation was analyzed after $72 \mathrm{~h}$ treatment using specific antibodies. Cells were harvested and incubated with Alexa488 anti-CD107a antibody (Biolegend, 1:50 in 0.1\% BSA) for $30 \mathrm{~min}$ at $4{ }^{\circ} \mathrm{C}$. Then, cells were washed and resuspended in $0.5 \mathrm{~mL}$ FluorFix ${ }^{\mathrm{TM}}$ Buffer (Biolegend) for $20 \mathrm{~min}$ at room temperature. Afterwards, cells were washed twice with $1 \times$ intracellular staining perm wash buffer and incubated with Alexa594 anti-Rab7a antibody (Biolegend, 1:50 in 0.1\% BSA) for $30 \mathrm{~min}$ at room temperature. The reaction was stopped with PBS and washed before cells were resuspended 
in $200 \mu \mathrm{L}$ PBS (+2 mM EDTA). Cells were analyzed by flow cytometry on a Flow Cytometer (FACSAriaII, BD, blue (488nm) and yellow-green (561 nm) laser). Data analysis was performed using BD FACSDiva software (BD).

\subsection{Senescence}

Senescence-associated $\beta$-galactosidase (SA- $\beta$-gal, Cell Signaling Technology, Cambridge, UK) was analyzed after $72 \mathrm{~h}$ of treatment. Cells were washed and fixed. After a second washing step, cells were stained with a Galactosidase Staining Solution. Therefore, cells were incubated at $37^{\circ} \mathrm{C}$ overnight in a dry incubator and checked for senescence the following day under a microscope. To analyze the number of senescent cells, ImageJ was used.

\subsection{Impedance Measurement and Actin Staining}

Impedance was measured with a commercial Electric Cell-Substrate Impedance Sensing system (ECIS Z9; Applied Biophysics, New York, NY, USA) equipped with a 96-well array station (Applied Biophysics) to monitor time and frequency dependent complex impedance, $Z(t, f)$. Cells were grown on a 96-well ECIS array plate with 20 interdigitated electrodes / well (96W20idf PET; ibidi GmbH, Gräfelfing, Germany). Prior to cell seeding, electrodes were stabilized with serum-free media overnight in the incubator with high humidity at $37{ }^{\circ} \mathrm{C}$ and $5 \% \mathrm{CO}_{2}$. Impedance measurements were performed directly in the treatment medium in the incubator, allowing real-time monitoring of all impedance alterations at 11 frequencies $(0.0625,0.125,0.25,0.5,1,2,4,8,16,32$, and $64 \mathrm{kHz})$ in a 180-s interval. $24 \mathrm{~h}$ after cell seeding, treatment was added for $72 \mathrm{~h}$. Analysis of cell-cell contacts was performed by $4000 \mathrm{kHz}$ using ECIS Software (Applied Biophysics).

To confirm the results of the impedance measurement, the actin filament was stained with phalloidin (1:300; Invitrogen, Darmstadt, Germany). Therefore, cells were treated for $72 \mathrm{~h}$ in Chamber Slides, fixed, permeabilized, stained, and analyzed as described for $\gamma-\mathrm{H} 2 \mathrm{AX}$.

\subsection{Wound Healing and Invasion Assay}

A wound healing assay was done in 12-well plates. After formation of a confluent cell layer, a defined scratch was set. Medium was removed, cells were washed with cell culture media, and the corresponding treatment based on the most promising simultaneous combinations was added. Scratch closure was documented by light microscopy routinely during the following $72 \mathrm{~h}$.

For the invasion assay, inserts $(8.0 \mu \mathrm{m}$ translucent; Greiner bio-one, Frickenhausen, Germany) were coated with $70 \mu \mathrm{L}$ Matrigel (1:25 in serum free media; Corning, NY, USA) and cells seeded in serum free, treatment containing media. The inserts were placed in a 24-well plate containing $750 \mu \mathrm{L}$ media with $10 \%$ FCS and incubated for $72 \mathrm{~h}$. Invasiveness was analyzed by WST-1 assay. The inserts were placed into a new 24-well plate containing WST-1 in serum free media. WST-1 containing medium without cells served as a blank. After $2.5 \mathrm{~h}$ of incubation, absorption was measured at a wavelength of $450 \mathrm{~nm}$.

\subsection{In Vivo Study \\ 4.11.1. Ethical Statement}

The German local authority approved all animal experiments: Landesamt für Landwirtschaft, Lebensmittelsicherheit und Fischerei Mecklenburg-Vorpommern (7221.3-1066/18), under the German animal protection law and the EU Guideline 2010/63/EU. Mice were bred in the animal facility of the University Medical Center in Rostock under specific pathogen-free conditions. All animals received enrichment in the form of mouse-igloos (ANT Tierhaltungsbedarf, Buxtehude, Germany), nesting material (shredded tissue paper, Verbandmittel GmbH, Frankenberg, Deutschland), paper roles (75 × 38 mm, H 0528-151, ssniff-Spezialdiäten $\mathrm{GmbH})$, and wooden sticks $(40 \times 16 \times 10 \mathrm{~mm}$, Abedd, Vienna, Austria). During the experiment, mice were kept in type III cages (Zoonlab GmbH, Castrop-Rauxel, 
Germany) at 12-h dark:light cycle, the temperature of $21 \pm 2{ }^{\circ} \mathrm{C}$, and relative humidity of $60 \pm 20 \%$ with food (pellets, $10 \mathrm{~mm}$, ssniff-Spezialdiäten $\mathrm{GmbH}$, Soest, Germany) and tap water ad libitum.

\subsubsection{Experimental Protocol}

Xenografts were generated by injecting $5 \times 10^{6}$ cells of UT-SCC-14 or UT_SCC-15 (in $50 \mu \mathrm{L}$ PBS) subcutaneously in the right flank of $6-8$ weeks old female NMRI Foxn $1^{\text {nu }}$ mice. Two weeks later, mice bearing tumors of $\sim 50 \mathrm{~mm}^{3}$ were allocated to treatment groups (Figure 7). Tumor diameters were measured with caliper every three to four days. Tumor volumes were calculated as (length $\times$ width $\left.^{2}\right) / 2$. Mice were euthanized before tumors reached $1500 \mathrm{~mm}^{3}$. Tumors were embedded in Cryomatrix (Thermo Scientific, Darmstadt, Germany) and used for HE staining.

\subsection{Statistics}

All values are expressed as mean $\pm \mathrm{SD}$ (in vitro analysis) or mean $\pm \mathrm{SEM}$ (in vivo therapy approach). Differences between controls and treated cells were determined by using one-way ANOVA (Bonferroni's Multiple Comparison Test) after proving the assumption of normality (Shapiro-Wilk test). If normality failed, the Kruskal Wallis test was applied. This information is given in the figure captions. Kaplan-Meier survival analysis was done by applying the log rank (Mantel Cox) test. Statistical evaluation was performed using GraphPad PRISM software, version 8.0.2 (GraphPad Software, San Diego, CA, USA). The criterion for significance was set to $p<0.05$.

\section{Conclusions}

Cyclin-dependent kinase inhibitors (CDKi) have broad therapeutic potential. Here, we show that CDKi's can be combined with standard cytostatic drugs and that dual CDK inhibition is at least as successful as CDKi/drug combinations. These findings contribute to our understanding of how the treatment of HNSCC can be improved prospectively. The complex effects exerted by specific CDKi-combinations include apoptotic and necrotic cell death as well as methuosis, an uncommon form of cell death, associated with vacuolization of macropinosome and endosome compartments. Dinaciclib and THZ1 were most effective and even better in combination with 5-FU. Another novel finding is the impact on actin fibers and motility properties of tumor cells by specific CDKi's. Prospective studies should focus on the effects on immune cells-especially because of the CDKi's potential to increase tumor immunogenicity.

Supplementary Materials: The following are available online at https:/ / www.mdpi.com/article/ 10.3390/cancers13102396/s1. Figure S1: Senescence, Figure S2: Scratch-Assay and Invasiveness UT-SCC-14., Figure S3: Influence on mitochondria, lysosomes, ER, and vacuole formation. Figure S4: Cell cycle analysis.

Author Contributions: Conceptualization, N.S. and C.M.; methodology, N.S., I.S., N.E., M.K., M.M., B.S., and C.R.; validation, N.S., C.M.; formal analysis, N.S.; investigation, N.S., I.S.; resources, C.M., C.J., N.E., and H.L.; data curation, N.S., N.E., M.K.; writing—original draft preparation, N.S., I.S.; writing-review and editing, C.M., C.G.-T., A.S.; visualization, N.S., C.M.; supervision, C.M.; project administration, C.M. All authors have read and agreed to the published version of the manuscript.

Funding: This research received no external funding.

Institutional Review Board Statement: The study was conducted according to the guidelines of the Declaration of Helsinki, and approved by the German local authority Ethics Committee) Landesamt für Landwirtschaft, Lebensmittelsicherheit und Fischerei Mecklenburg-Vorpommern, under the German animal protection law and the EU Guideline 2010/63/EU (protocol code: 7221.3-1-066/18 and date of approval: 15 January 2019).

Informed Consent Statement: Not applicable. 
Data Availability Statement: The data presented in this study are available in this article (and supplementary material).

Acknowledgments: The patient-derived cell lines UT-SCC-14 and UT-SCC15 were kindly provided by Reidar Grénman (Turku University Hospital, Turku, Finland).

Conflicts of Interest: The authors declare no conflict of interest.

\section{References}

1. Schafer, K.A. The Cell Cycle: A review. Vet. Pathol. 1998, 35, 461-478. [CrossRef]

2. Jingwen, B.; Yaochen, L.; Guojun, Z. Cell cycle regulation and anticancer drug discovery. Cancer Biol. Med. 2017, 14, 348. [CrossRef] [PubMed]

3. Roskoski, R. Cyclin-dependent protein serine/threonine kinase inhibitors as anticancer drugs. Pharmacol. Res. 2019, 139, 471-488. [CrossRef] [PubMed]

4. Sánchez-Martínez, C.; Lallena, M.J.; Sanfeliciano, S.G.; de Dios, A. Cyclin dependent kinase (CDK) inhibitors as anticancer drugs: Recent advances (2015-2019). Bioorgan. Med. Chem. Lett. 2019, 29, 126637. [CrossRef] [PubMed]

5. Asghar, U.; Witkiewicz, A.K.; Turner, N.C.; Knudsen, E.S. The history and future of targeting cyclin-dependent kinases in cancer therapy. Nat. Rev. Drug Discov. 2015, 14, 130-146. [CrossRef]

6. Patel, V.; Jakus, J.; Harris, C.M.; Ensley, J.F.; Robbins, K.C.; Yeudall, W.A. Altered expression and activity of G1/S cyclins and cyclin-dependent kinases characterize squamous cell carcinomas of the head and neck. Int. J. Cancer 1997, 73, 551-555. [CrossRef]

7. Parry, D.; Guzi, T.; Shanahan, F.; Davis, N.; Prabhavalkar, D.; Wiswell, D.; Seghezzi, W.; Paruch, K.; Dwyer, M.P.; Doll, R.; et al. Dinaciclib (SCH 727965), a novel and potent cyclin-dependent kinase inhibitor. Mol. Cancer Ther. 2010, 9, 2344-2353. [CrossRef] [PubMed]

8. $\quad$ Paruch, K.; Dwyer, M.P.; Alvarez, C.; Brown, C.; Chan, T.Y.; Doll, R.J.; Keertikar, K.; Knutson, C.; McKittrick, B.; Rivera, J.; et al. Discovery of dinaciclib (SCH 727965): A potent and selective inhibitor of cyclin-dependent kinases. ACS Med. Chem. Lett. 2010, 1, 204-208. [CrossRef]

9. Schoninger, S.F.; Blain, S.W. The Ongoing Search for Biomarkers of CDK4/6 Inhibitor Responsiveness in Breast Cancer. Mol. Cancer Ther. 2020, 19, 3-12. [CrossRef] [PubMed]

10. Greber, B.J.; Perez-Bertoldi, J.M.; Lim, K.; Iavarone, A.T.; Toso, D.B.; Nogales, E. The cryoelectron microscopy structure of the human CDK-activating kinase. Proc. Natl. Acad. Sci. USA 2020, 117, 22849-22857. [CrossRef] [PubMed]

11. Grünwald, V.; Chirovsky, D.; Cheung, W.Y.; Bertolini, F.; Ahn, M.J.; Yang, M.H.; Castro, G.; Berrocal, A.; Sjoquist, K.; Kuyas, H.; et al. Global treatment patterns and outcomes among patients with recurrent and/or metastatic head and neck squamous cell carcinoma: Results of the GLANCE H\&N study. Oral Oncol. 2020, 102, 104526. [PubMed]

12. Bray, F.; Ferlay, J.; Soerjomataram, I.; Siegel, R.L.; Torre, L.A.; Jemal, A. Global cancer statistics 2018: GLOBOCAN estimates of incidence and mortality worldwide for 36 cancers in 185 countries. CA. Cancer J. Clin. 2018, 68, 394-424. [CrossRef]

13. Gebre-Medhin, M.; Brun, E.; Engström, P.; Haugen Cange, H.; Hammarstedt-Nordenvall, L.; Reizenstein, J.; Nyman, J.; Abel, E.; Friesland, S.; Sjödin, H.; et al. ARTSCAN III: A Randomized Phase III Study Comparing Chemoradiotherapy With Cisplatin Versus Cetuximab in Patients With Locoregionally Advanced Head and Neck Squamous Cell Cancer. J. Clin. Oncol. 2021, 39, 38-47. [CrossRef] [PubMed]

14. McDermott, J.D.; Bowles, D.W. Epidemiology of Head and Neck Squamous Cell Carcinomas: Impact on Staging and Prevention Strategies. Curr. Treat. Options Oncol. 2019, 20, 1-13. [CrossRef] [PubMed]

15. Salakova, M.; Koslabova, E.; Grega, M.; Smahelova, J.; Klozar, J.; Vencalek, O.; Tachezy, R. Mucosal and skin HPV types in tumour-free tonsils and tonsillar tumours. Neoplasma 2018, 65, 278-286. [CrossRef]

16. Adkins, D.; Ley, J.; Neupane, P.; Worden, F.; Sacco, A.G.; Palka, K.; Grilley-Olson, J.E.; Maggiore, R.; Salama, N.N.; Trinkaus, K.; et al. Palbociclib and cetuximab in platinum-resistant and in cetuximab-resistant human papillomavirus-unrelated head and neck cancer: A multicentre, multigroup, phase 2 trial. Lancet Oncol. 2019, 20, 1295-1305. [CrossRef]

17. Yoon, N.; Vander Velde, R.; Marusyk, A.; Scott, J.G. Optimal Therapy Scheduling Based on a Pair of Collaterally Sensitive Drugs. Bull. Math. Biol. 2018, 80, 1776-1809. [CrossRef] [PubMed]

18. Li, Y.F.; Chang, L.; Li, W.H.; Xiao, M.Y.; Wang, Y.; He, W.J.; Xia, Y.X.; Wang, L.; Chen, Y. Radiotherapy concurrent versus sequential with endocrine therapy in breast cancer: A meta-analysis. Breast 2016, 27, 93-98. [CrossRef]

19. Robinson, A.M.; Rathore, R.; Redlich, N.J.; Adkins, D.R.; VanArsdale, T.; Van Tine, B.A.; Michel, L.S. Cisplatin exposure causes c-Myc-dependent resistance to CDK4/6 inhibition in HPV-negative head and neck squamous cell carcinoma. Cell Death Dis. 2019, 10, 867. [CrossRef]

20. Northcott, J.M.; Dean, I.S.; Mouw, J.K.; Weaver, V.M. Feeling stress: The mechanics of cancer progression and aggression. Front. Cell Dev. Biol. 2018, 6, 1-12. [CrossRef]

21. Humphries, W.H.; Szymanski, C.J.; Payne, C.K. Endo-lysosomal vesicles positive for rab7 and lamp1 are terminal vesicles for the transport of dextran. PLoS ONE 2011, 6, e26626. [CrossRef]

22. Shah, A.; Bloomquist, E.; Tang, S.; Fu, W.; Bi, Y.; Liu, Q.; Yu, J.; Zhao, P.; Palmby, T.R.; Goldberg, K.B.; et al. FDA approval: Ribociclib for the treatment of postmenopausal women with hormone receptor-positive, HER2-negative advanced or metastatic breast cancer. Clin. Cancer Res. 2018, 24, 2999-3004. [CrossRef] 
23. Groenland, S.L.; Martínez-Chávez, A.; van Dongen, M.G.J.; Beijnen, J.H.; Schinkel, A.H.; Huitema, A.D.R.; Steeghs, N. Clinical Pharmacokinetics and Pharmacodynamics of the Cyclin-Dependent Kinase 4 and 6 Inhibitors Palbociclib, Ribociclib, and Abemaciclib. Clin. Pharmacokinet. 2020, 59, 1501-1520. [CrossRef] [PubMed]

24. Göttgens, E.L.; Bussink, J.; Leszczynska, K.B.; Peters, H.; Span, P.N.; Hammond, E.M. Inhibition of CDK4/CDK6 Enhances Radiosensitivity of HPV Negative Head and Neck Squamous Cell Carcinomas. Int. J. Radiat. Oncol. Biol. Phys. 2019, 105, 548-558. [CrossRef]

25. Billard-Sandu, C.; Tao, Y.G.; Sablin, M.P.; Dumitrescu, G.; Billard, D.; Deutsch, E. CDK4/6 inhibitors in P16/HPV16-negative squamous cell carcinoma of the head and neck. Eur. Arch. Oto-Rhino-Laryngol. 2020, 277, 1273-1280. [CrossRef] [PubMed]

26. Deep, G.; Agarwal, R. New combination therapies with cell-cycle agents. Curr. Opin. Investig. Drugs 2008, 9, 591-604.

27. Shah, M.A.; Schwartz, G.K. Cell cycle-mediated drug resistance: An emerging concept in cancer therapy. Clin. Cancer Res. 2001, 7, 2168-2181. [PubMed]

28. Weiss, J.M.; Csoszi, T.; Maglakelidze, M.; Hoyer, R.J.; Beck, J.T.; Domine Gomez, M.; Lowczak, A.; Aljumaily, R.; Rocha Lima, C.M.; Boccia, R.V.; et al. Myelopreservation with the CDK4/6 inhibitor trilaciclib in patients with small-cell lung cancer receiving first-line chemotherapy: A phase Ib/randomized phase II trial. Ann. Oncol. 2019, 30, 1613-1621. [CrossRef] [PubMed]

29. Hart, L.L.; Ferrarotto, R.; Andric, Z.G.; Beck, J.T.; Subramanian, J.; Radosavljevic, D.Z.; Zaric, B.; Hanna, W.T.; Aljumaily, R.; Owonikoko, T.K.; et al. Myelopreservation with Trilaciclib in Patients Receiving Topotecan for Small Cell Lung Cancer: Results from a Randomized, Double-Blind, Placebo-Controlled Phase II Study. Adv. Ther. 2021, 38, 350-365. [CrossRef]

30. Mitri, Z.; Karakas, C.; Wei, C.; Briones, B.; Simmons, H.; Ibrahim, N.; Alvarez, R.; Murray, J.L.; Keyomarsi, K.; Moulder, S. A phase 1 study with dose expansion of the CDK inhibitor dinaciclib (SCH 727965) in combination with epirubicin in patients with metastatic triple negative breast cancer. Invest. New Drugs 2015, 33, 890-894. [CrossRef] [PubMed]

31. Kumar, S.K.; LaPlant, B.; Chng, W.J.; Zonder, J.; Callander, N.; Fonseca, R.; Fruth, B.; Roy, V.; Erlichman, C.; Stewart, A.K.; et al. Dinaciclib, a novel CDK inhibitor, demonstrates encouraging single-agent activity in patients with relapsed multiple myeloma. Blood 2015, 125, 443-448. [CrossRef]

32. Riess, C.; Irmscher, N.; Salewski, I.; Strüder, D.; Classen, C.F.; Große-Thie, C.; Junghanss, C.; Maletzki, C. Cyclin-dependent kinase inhibitors in head and neck cancer and glioblastoma-backbone or add-on in immune-oncology? Cancer Metastasis Rev. 2020, 40, 153-171. [CrossRef] [PubMed]

33. Md Sakib Hossain, D.; Javaid, S.; Cai, M.; Zhang, C.; Sawant, A.; Hinton, M.; Sathe, M.; Grein, J.; Blumenschein, W.; Pinheiro, E.M.; et al. Dinaciclib induces immunogenic cell death and enhances anti- PD1-mediated tumor suppression. J. Clin. Investig. 2018, 128, 644-654. [CrossRef] [PubMed]

34. Zhang, Y.; Zhou, L.; Bandyopadhyay, D.; Sharma, K.; Allen, A.J.; Kmieciak, M.; Grant, S. The covalent CDK7 inhibitor THz1 potently induces apoptosis in multiple myeloma cells in vitro and in vivo. Clin. Cancer Res. 2019, 25, 6195-6205. [CrossRef]

35. Wang, T.H.; Chen, C.C.; Leu, Y.L.; Lee, Y.S.; Lian, J.H.; Hsieh, H.L.; Chen, C.Y. Palbociclib induces DNA damage and inhibits DNA repair to induce cellular senescence and apoptosis in oral squamous cell carcinoma. J. Formos. Med. Assoc. 2020. [CrossRef]

36. Wagner, V.; Gil, J. Senescence as a therapeutically relevant response to CDK4/6 inhibitors. Oncogene 2020, 39, 5165-5176. [CrossRef] [PubMed]

37. Dominiak, A.; Chełstowska, B.; Olejarz, W.; Nowicka, G. Communication in the cancer microenvironment as a target for therapeutic interventions. Cancers 2020,12, 1232. [CrossRef]

38. Zhang, N.; Yin, Y.; Xu, S.J.; Chen, W.S. 5-Fluorouracil: Mechanisms of resistance and reversal strategies. Molecules 2008, 13, 1551-1569. [CrossRef]

39. Brückner, B.R.; Nöding, H.; Skamrahl, M.; Janshoff, A. Mechanical and morphological response of confluent epithelial cell layers to reinforcement and dissolution of the F-actin cytoskeleton. Prog. Biophys. Mol. Biol. 2019, 144, 77-90. [CrossRef]

40. Shannon, S.; Jia, D.; Entersz, I.; Beelen, P.; Yu, M.; Carcione, C.; Carcione, J.; Mahtabfar, A.; Vaca, C.; Weaver, M.; et al. Inhibition of glioblastoma dispersal by the MEK inhibitor PD0325901. BMC Cancer 2017, 17, 121. [CrossRef]

41. Yaromina, A.; Zips, D.; Thames, H.D.; Eicheler, W.; Krause, M.; Rosner, A.; Haase, M.; Petersen, C.; Raleigh, J.A.; Quennet, V.; et al. Pimonidazole labelling and response to fractionated irradiation of five human squamous cell carcinoma (hSCC) lines in nude mice: The need for a multivariate approach in biomarker studies. Radiother. Oncol. 2006, 81, 122-129. [CrossRef] [PubMed]

42. Chugh, P.; Paluch, E.K. The actin cortex at a glance. J. Cell Sci. 2018, 131, 1-9. [CrossRef]

43. Gardai, S.J.; McPhillips, K.A.; Frasch, S.C.; Janssen, W.J.; Starefeldt, A.; Murphy-Ullrich, J.E.; Bratton, D.L.; Oldenborg, P.A.; Michalak, M.; Henson, P.M. Cell-surface calreticulin initiates clearance of viable or apoptotic cells through trans-activation of LRP on the phagocyte. Cell 2005, 123, 321-334. [CrossRef]

44. Kroemer, G.; Galluzzi, L.; Kepp, O.; Zitvogel, L. Immunogenic Cell Death in Cancer Therapy. Ann. Rev. Immunol. 2013, 31, 51-72. [CrossRef]

45. Riess, C.; Schneider, B.; Kehnscherper, H.; Gesche, J.; Irmscher, N.; Shokraie, F.; Classen, C.F.; Wirthgen, E.; Domanska, G.; Zimpfer, A.; et al. Activation of the Kynurenine Pathway in Human Malignancies Can Be Suppressed by the Cyclin-Dependent Kinase Inhibitor Dinaciclib. Front. Immunol. 2020, 11, 55. [CrossRef]

46. Li, B.B.; Khan, N.; Ubellacker, J.M.; Xie, S.; Metzger-filho, O.; Roberts, T.M.; Kim, H.; Mcallister, S.S.; Jean, J. CDK4/6 inhibition triggers anti-tumor immunity. Nature 2017, 548, 471-475.

47. Wang, J.; Yang, T.; Xu, G.; Liu, H.; Ren, C.; Xie, W.; Wang, M. Cyclin-dependent kinase 2 promotes tumor proliferation and induces radio resistance in glioblastoma. Transl. Oncol. 2016, 9, 548-556. [CrossRef] [PubMed] 
48. Xie, X.; Zheng, W.; Chen, T.; Lin, W.; Liao, Z.; Liu, J.; Ding, Y. CDK4/6 inhibitor palbociclib amplifies the radiosensitivity to nasopharyngeal carcinoma cells via mediating apoptosis and suppressing DNA damage repair. Onco. Targets. Ther. 2019, 12, 11107-11117. [CrossRef] [PubMed]

49. Olson, C.M.; Liang, Y.; Leggett, A.; Park, W.D.; Li, L.; Mills, C.E.; Elsarrag, S.Z.; Ficarro, S.B.; Zhang, T.; Düster, R.; et al. Development of a Selective CDK7 Covalent Inhibitor Reveals Predominant Cell-Cycle Phenotype. Cell Chem. Biol. 2019, 26, 792-803.e10. [CrossRef]

50. Veo, B.; Danis, E.; Pierce, A.; Wang, D.; Fosmire, S.; Sullivan, K.D.; Joshi, M.; Khanal, S.; Dahl, N.; Karam, S.; et al. Transcriptional control of DNA repair networks by CDK7 regulates sensitivity to radiation in Myc-driven medulloblastoma. Cell Rep. 2021, 35, 109013. [CrossRef]

51. Pessina, F.; Giavazzi, F.; Yin, Y.; Gioia, U.; Vitelli, V.; Galbiati, A.; Barozzi, S.; Garre, M.; Oldani, A.; Flaus, A.; et al. Functional transcription promoters at DNA double-strand breaks mediate RNA-driven phase separation of damage-response factors. Nat. Cell Biol. 2019, 21, 1286-1299. [CrossRef] [PubMed]

52. Krajewska, M.; Dries, R.; Grassetti, A.V.; Dust, S.; Gao, Y.; Huang, H.; Sharma, B.; Day, D.S.; Kwiatkowski, N.; Pomaville, M.; et al. CDK12 loss in cancer cells affects DNA damage response genes through premature cleavage and polyadenylation. Nat. Commun. 2019, 10, 1757. [CrossRef]

53. Maskey, R.S.; Wang, F.; Lehman, E.; Wang, Y.; Emmanuel, N.; Zhong, W.; Jin, G.; Abraham, R.T.; Arndt, K.T.; Myers, J.S.; et al. Sustained mTORC1 activity during palbociclib-induced growth arrest triggers senescence in ER+ breast cancer cells. Cell Cycle 2020, 20, 65-80. [CrossRef]

54. Yu, Y.; Liao, H.; Xie, R.; Zhang, Y.; Zheng, R.; Chen, J.; Zhang, B. Overexpression of miRNA-3613-3p Enhances the Sensitivity of Triple Negative Breast Cancer to CDK4/6 Inhibitor Palbociclib. Front. Oncol. 2020, 10, 2541. [CrossRef] [PubMed]

55. Vijayaraghavan, S.; Karakas, C.; Doostan, I.; Chen, X.; Bui, T.; Yi, M.; Raghavendra, A.S.; Zhao, Y.; Bashour, S.I.; Ibrahim, N.K.; et al. CDK4/ 6 and autophagy inhibitors synergistically induce senescence in Rb positive cytoplasmic cyclin e negative cancers. Nat. Commun. 2017, 8, 15916. [CrossRef]

56. Focaccetti, C.; Bruno, A.; Magnani, E.; Bartolini, D.; Principi, E.; Dallaglio, K.; Bucci, E.O.; Finzi, G.; Sessa, F.; Noonan, D.M.; et al. Effects of 5-Fluorouracil on Morphology, Cell Cycle, Proliferation, Apoptosis, Autophagy and ROS Production in Endothelial Cells and Cardiomyocytes. PLoS ONE 2015, 10, e0115686. [CrossRef]

57. Tokunaga, E.; Oda, S.; Fukushima, M.; Maehara, Y.; Sugimachi, K. Differential growth inhibition by 5-fluorouracil in human colorectal carcinoma cell lines. Eur. J. Cancer 2000, 36, 1998-2006. [CrossRef]

58. Schachter, M.M.; Fisher, R.P. The CDK-activating kinase Cdk7. Cell Cycle 2013, 12, 3239-3240. [CrossRef] [PubMed]

59. Higashi, H.; Suzuki-Takahashi, I.; Saitoh, S.; Segawa, K.; Taya, Y.; Okuyama, A.; Nishimura, S.; Kitagawa, M. Cyclin-dependent kinase-2 (Cdk2) forms an inactive complex with cyclin D1 since Cdk2 associated with cyclin D1 is not phosphorylated by Cdk7-cyclin-H. Eur. J. Biochem. 1996, 237, 460-467. [CrossRef]

60. Riess, C.; Koczan, D.; Schneider, B.; Linke, C.; del Moral, K.; Classen, C.F.; Maletzki, C. Cyclin-dependent kinase inhibitors exert distinct effects on patient-derived 2D and 3D glioblastoma cell culture models. Cell Death Discov. 2021, 7, 54. [CrossRef]

61. Maltese, W.A.; Overmeyer, J.H. Methuosis: Nonapoptotic cell death associated with vacuolization of macropinosome and endosome compartments. Am. J. Pathol. 2014, 184, 1630-1642. [CrossRef]

62. Ghosh, S. Cisplatin: The first metal based anticancer drug. Bioorg. Chem. 2019, 88, 102925. [CrossRef] [PubMed]

63. Dasari, S.; Bernard Tchounwou, P. Cisplatin in cancer therapy: Molecular mechanisms of action. Eur. J. Pharmacol. 2014, 740, 364-378. [CrossRef] [PubMed]

64. Chen, X.X.; Xie, F.F.; Zhu, X.J.; Lin, F.; Pan, S.S.; Gong, L.H.; Qiu, J.G.; Zhang, W.J.; Jiang, Q.W.; Mei, X.L.; et al. Cyclindependent kinase inhibitor dinaciclib potently synergizes with cisplatin in preclinical models of ovarian cancer. Oncotarget 2015, 6, 14926-14939. [CrossRef] [PubMed]

65. Egeblad, M.; Nakasone, E.S.; Werb, Z. Tumors as organs: Complex tissues that interface with the entire organism. Dev. Cell 2010, 18, 884-901. [CrossRef] [PubMed] 